\title{
Diverting The Coasean River: Incentive Schemes To Reduce Unemployment Spells
}

\author{
John J. Donohue III†
}

The immense literature generated by Ronald Coase's original exposition of the "Coase Theorem" demonstrates the theoretical depth and richness of one of the seminal works of Law and Economics. ${ }^{1}$ Ultimately, however, the value of the Coase Theorem to law and to social science rests upon the extent to which the brilliant theory is empirically validated. ${ }^{2}$ This Article examines the results of a labor-market experiment conducted

+ Northwestern University School of Law, American Bar Foundation. I would like to thank Ian Ayres, Charlotte Crane, Ronald Coase, Richard Craswell, Harold Demsetz, Marijke Donohue, Mark Grady, David Haddock, Keith Hylton, Daniel Klerman, Saul Levmore, Dan Polsby, Richard Posner, George Priest, Carol Rose, Marshall Shapo, Peter Siegelman, Stewart Schwab, George Stigler, Jeff Strnad, and participants at faculty workshops at Northwestern University School of Law, Yale Law School, the University of Southern California Law School, and the Labor Economics workshop at Northwestern University for their helpful comments. Bruce Meyer, who set up the public use data tapes from the Illinois experiment at Northwestern, also deserves thanks for making them available to me. Finally, Stephen Woodbury, whose assistance I gratefully acknowledge, supplied information on the experiment's design and results. An earlier version of this paper was the 1989 winner of the Scholarly Paper Competition of the Association of American Law Schools.

1. Coase, The Problem of Social Cost, 3 J.L. \& EcoN. 1 (1960). The theorem is widely regarded as "the centerpiece of law and economics scholarship," Schwab, Collective Bargaining and the Coase Theorem, 72 Cornell L. Rev. 245, 246 (1987). Judge Posner, however, has opined that in a review essay on the cconomic approach to law I overstated the significance of the Coase Theorem. Posner, Comment on Donohue, 22 LAw \& Soc'y REv. 927 (1988) (discussing Donohue, Law and Economics: The Road Not Taken, 22 Law \& Soc'y REv. 903 (1988)) ("I would not emphasize the Coase Theorem as much as Donohue does. The essential relevance of economics to law lies not in a particular theorem but in the fact that economics is the most advanced of the social sciences."). A LEXIS search reveals that Coase's famous article has been cited in seven state cases, one Federal district court case, 17 court of appeals cases, and one U.S. Supreme Court case.

2. Coase himself has stressed that his theorem is valuable only to the extent that it offers insights into "the real world." His remarks came in response to the argument that when more than two parties are involved, one cannot always expect costless bargaining to lead to Pareto-optimal outcomes. Coase, The Caase Theorem and the Empty Core: A Comment, 24 J.L. \& Econ. 183, 187 (1981). Using a game-theoretic approach, Aivazian and Callen argued that the optimal solution among three or more parties may be unstable if the payoffs are arrayed in such a fashion that different coalitions could always secure greater profits for themselves by defecting irom any overall agreement. Aivazian \& Callen, The Coase Theorem and the Empty Core, 24 J.L. \& Econ. 175 (1981). Coase responded that with zero transaction costs a contract would be entered into which would make the grand coalition stable. He then issued the following admonition:

[W] hile consideration of what would happen in a world of zero transaction costs can give us valuable insights, these insights are, in my view, without value except as steps on the way to the analysis of the real world of positive transaction costs. We do not do well to devote ourselves to a detailed study of the world of zero transaction costs, like augurs divining the future by the minute inspection of the entrails of a goose.

Coase, supra, at 187. 
by the state of Illinois that provides the first real-world test of the three main tenets of the Coase Theorem: the efficiency, invariance, and distribution predictions. The efficiency prediction asserts that in a world of zero transaction costs parties will bargain to efficient outcomes regardless of the assignment of the initial legal entitlement. The invariance prediction asserts that in the absence of wealth effects the allocation of resources will be invariant to the legal rule. ${ }^{3}$ The distributional prediction asserts that under certain circumstances the assignment of the initial legal entitlement will not affect the distribution of wealth. ${ }^{4}$

3. The invariance prediction applies at least in the short run and possibly in the long run as well. Coase argued that the allocation of the particular good or service in question will remain invariant to changes in the legal rule. George Stigler has found this thesis to be "extraordinarily unobvious." Stigler writes:

The same amount of smoke would be released from the factory's chimney whether the factory owner or the householder was legally responsible for the smoke damage. If this proposition strikes you as incredible on first hearing, join the club. The world of zero transaction costs turns out to be as strange as the physical world would be with zero friction.

Stigler, The Law and Economics of Public Policy: A Plea to the Scholars, 1 J. Legal Stud. 1, 11-12 (1972). For a spirited defense of the invariance thesis, see Demsetz, When Does the Rule of Liability Matter?, 1 J. Legal Stud. 13 (1972).

In Law and Economics: The Road Not Taken, supra note 1, I discuss how the presence of wealth effects clearly undermines the invariance thesis, and I examine the confusion this issue has generated. Most analysts now agree, however, that in the absence of wealth effects the invariance thesis is correct at least in the short run and at least for property rules if not for liability rules.

The debate rages, however, over whether the thesis is correct in the long run. See generally Schwab, supra note 1, at 273-75 (discussing how long-run effects of legal rules tend to confirm Coasean predictions). Regan denounces the invariance thesis, Regan, The Problem of Social Cost Revisited, 15 J.L. \& EcoN. 427, 432-33 (1972), and Cooter dismisses it with a wave of his hand, Cooter, The Cost of Coase, 11 J. Legal STud. 1, 15 (1982) ("now there is agreement that the invariance version is untenable"). Auten expresses the view of the critics of Coase on this point: "In Coase's examples the results will ... . vary with liability depending on the Ricardian rents of pollutors and receptors. If both pollutor and receptor operate on marginal land the pollutor must cease operations in the long run if liable, and the receptor will be driven out if liable." Auten, Discussion, in Theory and Measurement of Economic Externalities 38 (S. Lin ed. 1976) (citation omitted).

But the advocates of the invariance thesis, when properly qualified, seem to have the better argument. See generally R. CoASE, The FIRM, THE MARKET, AND THE LAw 163-70 (1988) (defending original example in terms of rents); Frech, The Extended Coase Theorem and Long Run Equilibrium: The Nonequivalence of Liability Rules and Property Rules, 17 EcoN. INQuiry 254 (1979) (invariance thesis applies in long run for property right assignments although not for liability rules); Zerbe, The Problem of Social Cost in Retrospect, 2 REs. L. \& ECON. 83 (1980). The answer to Auten is that, if the land is marginal and transaction costs are truly zero, then both the polluter and receptor are equally happy to move (costlessly) to another location, regardless of the rule of liability. If one party is earning rents and the other is not, the party earning rents will remain, and the marginal enterprise will cease operation, again without regard to the legal rule.

4. Demsetz, supra note 3, at 16-18 (1972) (property rights affect wealth distribution, but contract rules do not); Schwab, Coase Defends Coase: Why Lawyers Listen and Economists Do Not, 87 Mfrch. L. REv. 1171, 1179 (1989). Consider the case in which the initial assignment of an entitlement is protected by a property right. Even when the invariance thesis holds and the level of a particular good or service consumed is unchanged by a shifting of an initial entitlement, the distribution of wealth between the parties will still be affected by a shift in the legal rule. That is, a rancher who is not liable for damage that her herd inflicts on farmers will find her income reduced if the legal rule changes to impose liability on ranchers for such crop damage.

Nonetheless, Coase demonstrates that, if transaction costs were zero, parties in the initial condition at the time of deciding whether to buy farmland or ranches would draft contracts to protect themselves against such changes in legal liability rules-thus holding constant the distribution of wealth at the time of the legal change.

[The contract would provide] that if ... the rule of law changed from one in which the 
Real-world tests of the Coasean efficiency prediction are rare because of the extraordinary difficulty of discerning efficient allocations. ${ }^{\circ}$ A given allocation of resources is Pareto-efficient, or Pareto-optimal, only if those resources cannot be reallocated so as to make at least one party better off without making another party worse off. Therefore, determining whether a given allocation is efficient requires precise information regarding the utility functions of all parties involved. One can more readily test the invariance prediction because it is easier to ascertain whether a legal shift changes the allocation of resources than to determine whether a given allocation is efficient. ${ }^{\circ}$

The invariance thesis, however, may not apply in the presence of wealth effects. For example, if allergy sufferer A wants to tear down a set of trees beloved by B that lies on their common boundary, the allocation of the entitlement to A may lead to deforestation while the allocation of the entitlement to B may leave the trees standing. Yet, although in this scena-

ranchers were not liable for the damage inflicted by their cattle to one in which they were liable, the amount which the ranchers would pay for the lease of their land would decrease and owners of ranching land would receive a rebate from those from whom they bought the land, while farmers would have to pay more for the lease of their land and owners of farming land wrould be required to make an additional payment to those from whom they bought the land. The distribution of wealth would remain the same.

R. COASE, supra note 3, at 173.

5. Ellickson's "microscopic" field research examining how the resolution of disputes over animal trespass is influenced by changing liability rules since 1945 is one of the few attempts at a real-world test of the Coase Theorem. Ellickson, Of Coase and Cattle: Dispute Resolution Among Neighbors in Shasta County, 38 STAN. L. REv. 623 (1986). Ellickson concludes that, while many of the assumptions undergirding the Coase Theorem are dubious, the central prediction that efficient outcomes will be reached "regardless of the specific content of law" is sound. $1 d$. at 686.

6 For an example of a test of the invariance prediction, see Vogel, The Coase Theorem and California Animal Trespass Law, 16 J. LEGAL. STud. 149 (1987) (exploring whether late nineteenth century agricultural production in California was influenced by changing rules of animal trespass). Although Vogel's study purports to demonstrate the failure of the Coasean invariance hypothesis, one must approach this conclusion with caution. Using a regression analysis of the effects of changes in animal trespass laws on agricultural production in California counties between 1850 and 1887, Vogel finds that "[c]hanges in the law had very consistent positive effects on the production of crops." Id. at 186.

But while Vogel's study is intriguing, its ultimate force is uncertain because of two potential econometric problems associated with his finding of a correlation between legal rules favorable to wheat farmers and high wheat production. First, since a shift to the favorable legal rule would enhance the wealth of farmers (even if the allocation of resources were invariant to the legal rule), one would expect farmers to press for such laws. If the political power of wheat farmers increases with their numbers, then one would expect the favorable laws to be found in counties with many wheat farmers and hence high wheat production. Thus, the direction of causation may be from high wheat production to a favorable law for wheat farmers, rather than vice versa as Vogel posits. Indeed, Ellickson tells us that California law favored cattlemen in 1850 when "[t]here was little farming" in the state, Ellickson, supra note 5 , at $660 \mathrm{n} .95$, but that this "pro-cattleman policy grew increasingly contraversial as . . . field crops became more common," id. at 660 .

The second problem is more technical than the first but is related to it. If one suspected that the change in the law caused the change in wheat production, then one should examine fluctuations in wheat production that occurred after the new law went into effect. But Vogel looks at the level of production during a five-year period centered on the enactment of the law. It is problematic, given his assumption that the law affects production, to use the law to explain the level of production for a period that begins two and one-half years before the law was enacted. This problem further underscores the basic "direction of causation" problem. 
rio the assignment of the initial legal entitlement may determine the outcome, such a scenario does not necessarily contradict the Coase Theorem because the allocation of the entitlement may have wealth effects that determine the parties' ability to pay and hence determine the efficient result. ${ }^{7}$

In sum, because of the difficulty of determining whether the efficiency prediction has been satisfied and because of potential wealth effects, which undermine the invariance claim, researchers will find it very difficult to test the Coase Theorem in a typical real-world setting. To circumvent these problems, a number of scholars have conducted innovative controlled experiments in which efficient outcomes were objectively established. ${ }^{8}$ These experiments, all of which use college or law students as subjects, have generally supported the Coasean efficiency and invariance predictions. ${ }^{9}$ But the very stylized nature of the controlled experimental setting raises some doubt that the same results would obtain under more complex, real-world conditions.

This article analyzes one real-world experiment that, although con-

7. If $\mathbf{A}$ had the right to destroy the trees and $\mathbf{B}$ happened to be relatively poor, $\mathrm{B}$ might be able and willing to pay only $\$ 1000$ to save the trees. If $B$ owned the entitlement, however, he would he wealthier; therefore, he might demand, say, $\$ 5000$ to allow their destruction. Under these circumstances the allocation of the entitlement would determine whether or not the trees were destroyed, so long as $A$ valued the defoliation at between $\$ 1000$ and $\$ 5000$. Such a state of affairs would be perfectly efficient.

Suppose, however, that $A$ valued the tree removal at only $\$ 500$. In this case, as long as $B$ values the trees at more than $\$ 500$, it would be an indication of the failure to achieve the efficient outcome if the allocation of the entitlement affected the ultimate fate of the trees: under the assumptions, the tree should be preserved in either event.

8. A typical experiment might involve two players who are told that one of them is to be given the choice to select among several options. The selecter can choose one option that pays him the most money directly or another option that yields the greatest sum of money to both individuals, the latter option being the efficient choice. The parties are informed that the non-selecter may try to inlluence the choice of the selecter by paying part or all of his earnings to the selecter. The conditions were therefore ideal for Coasean bargaining: there is a clear joint-maximizing choice, side payments are allowed, and contracts are in writing and strictly enforced. See generally Coursey, Hoffman \& Spitzer, Fear and Loathing in the Coase Theorem: Experimental Tests Involving Physical Discomfort, 16 J. LEGAL STUD. 217, 247 (1987) (describing such an experiment); Harrison \& McKee, Experimental Evaluation of the Coase Theorem, 28 J.L. \& EcoN. 653, 666 (1985) (same); Hoffman \& Spitzer, The Coase Theorem: Some Experimental Tests, 25 J.L. \& Econ. 73, 83 (1982) (same) [hereinafter Some Experimental Tests]; Hoffman \& Spitzer, Entitlements, Rights, and Fairness: An Experimental Examination of Subjects' Concepts of Distributive Justice, 14 J. LEGAL STUD. 259, 269 (1985) (same) [hereinafter Entitlements, Rights, and Fairness]; Hoffman \& Spitzer, Experimcntal Tests of the Coase Theorem With Large Bargaining Groups, 15 J. LEGAL. Stud. 149, 153 (1986) (describing such an experiment with bargaining groups composed of numerous individuals) (hereinafter Large Bargaining Groups]; Schwab, A Coasean Experiment on Contract Presumptions, $17 \mathrm{~J}$. LEGAL STUD. 237 (1988) (describing and analyzing such an experiment with 222 paired subjects).

9. See sources cited supra note 8. The exception is the experiment in which law students and industrial-and-labor-relations students negotiated a simulated collective bargaining agreement and "only 20 percent of the contracts were efficient in all respects . . ." Schwab, supra note 8, at 264. It is also worth noting that the initial Hoffman and Spitzer article, although confirming Coase's efficiency prediction, did not conform to Coase's distribution prediction because the parties usually split the total payout, even though this left one party with less than his initial endowment. Hoftman \& Spitzer, Some Experimental Tests, supra note 8, at 93. The authors note that "[i]t is possible that we would have observed fewer equal splits if we had not used college students as subjects. College students may not be as rationally self-interested as those who are older." Id. 
ducted for other reasons, is particularly well suited to shed light on the operation of the Coase Theorem. The problems facing most real-world tests of the Coase Theorem were absent in this experiment: (1) certain obviously inefficient outcomes were readily identified; (2) since wealth effects were absent, the invariance prediction applied; and (3) the circumstances were such that one would predict that the legal assignment would not alter the distribution of income. Moreover, since the test was originally undertaken without any interest in or awareness of the Coase Theorem, those involved in the experiment were not subtly signalled to act either in furtherance or in defiance of Coasean predictions.

The state of Illinois designed and conducted this experiment to ascertain whether incentive payments to workers or to their employers could lead to a reduction in the length of time that unemployed workers remained on unemployment compensation following loss of a job, and if so, which system worked better-the worker-payment system or the employer-payment system. For the workers to qualify for bonuses under the worker-payment system, or for the employers to qualify for bonuses under the employer-payment system, the workers (who were new unemployment compensation claimants) had to return to work within eleven weeks of losing a job and remain on the new job for four months. Under the worker-payment system, workers who satisfied these criteria received a lump-sum payment of $\$ 500$. Under the employer-payment system, the employers of those workers satisfying the criteria received the lump-sum payment of $\$ 500$. Whether the payment was structured to go initially to the worker or to the employer, the Coase Theorem predicts that if transaction costs had been zero the parties would have established an employment contract whenever the bonus was sufficient to enable a mutually advantageous bargain to be struck. In other words, Pareto efficiency should have been achieved under either payment scheme. ${ }^{10}$ In addition to the promise of efficiency, the Coase Theorem would predict that in a world of perfect information and zero transaction costs the results for the two payment schemes would be identical in terms of both the allocation and the distribution of resources.

Part I describes the details of the Illinois experiment. Part II introduces the notion of the Coasean identity prediction and demonstrates that under the assumption of zero transaction costs this prediction applies in the Illinois experiment. Understanding that transactions costs are always positive, I then discuss the reasons for thinking that these costs may have been

10. If one thinks of efficiency as expanding the size of the pie, then clearly the pie that the ermployer and employec divided would be greater if the state added a $\$ 500$ bonus to the establishment of an employment relationship. An obvious departure from efficiency would have occurred, however, if parties frequently did not pursue the $\$ 500$ bonus when they met all the conditions for obtaining it. I therefore consider efficiency from the perspectives of the parties rather than from the perspective of the state. 
substantially lower in this situation than in many other real-world settings. That the experiment involved only two parties-an employer and a potential employee-who were not locked in a bilateral monopoly and who already had to negotiate an employment contract suggests that the incremental transaction costs in dividing or re-assigning the bonus would be modest. Consequently, the combination of strong theoretical predictions and the relatively low transaction costs make the Illinois experiment a good vehicle for exploring the operation of the Coase Theorem.

Part III discusses the results of the experiment, which conflict with Coasean predictions in that (1) the parties frequently failed to collect bonuses to which they were entitled (in contravention of the efficiency prediction); (2) the workers made far more use of the worker-payment program than of the employer-payment program (in contravention of the invariance prediction); and (3) the distribution of income depended upon whether the bonus was paid to workers or to employers (in contravention of the distribution prediction).

Part IV provides possible reasons for the divergence from Coasean predictions. For example, this Part examines the possibility that strategic behavior might have increased the need to enforce agreements concerning the split of the bonus, thereby significantly elevating transaction costs. Also discussed is the extent to which asymmetries in the two bonus schemes - such as tax considerations and stigmatization by a governmental program - can explain the results of the experiment. Part IV also examines the extent to which the results of the Illinois experiment directly contradict the Coase Theorem because of the inability to perceive bargaining opportunities on the part of the individuals involved, because of their tendency to accept authoritarian determinations, or because the assignment of legal entitlements altered the psychology of bargaining. Finally, Part V concludes with an examination of the policy implications that might be drawn from the results of the Illinois experiment.

\section{The Experimental Design}

The Illinois Department of Employment Security conducted the bonus payment experiment between mid-1984 and mid-1985.11 Three groups, each consisting of roughly 4000 unemployment compensation recipients, were randomly selected: the worker-payment group (WPG), in which workers received bonuses if they returned to work within eleven weeks of initially filing for unemployment and remained at work for at least four months; the employer-payment group (EPG), in which, if the workers

11. Further discussion of the details of the experiment can be found in R. Spiegelman \& S. Woodbury, The Illinois Unemployment Insurance Incentive Experiments: Final Report (Feb. 1987) (manuscript on file with the author) [hereinafter Final Report], and Woodbury \& Spiegelman, Bonuses to Workers and Employers to Reduce Unemployment: Randomized Trials in Illinois, 77 AM. ECON. Rev. 513 (1987) [hereinafter Randomized Trials in Illinois]. 
met the above conditions, their employers received the bonus; and the control group, in which neither the workers nor their employers were eligible for bonuses. ${ }^{12}$ Claimants assigned to either the WPG or the EPG were asked to sign an "agreement to participate," and those who did so were mailed a packet of administrative and instructional materials. ${ }^{13}$ If within eleven weeks of filing an initial unemployment insurance claim, any member of either group accepted employment of at least thirty hours per week, she was instructed to file (or, under the EPG program, have the employer file) a Notice of Hire form (NOH) with the Illinois Department of Employment Security. The Department then returned a voucher to the worker (or, under the EPG, to the employer). If the worker remained on the job for at least four months, the voucher could be submitted by the appropriate party for a $\$ 500$ cash bonus. ${ }^{14}$

\section{Coasean Predictions: Should the Assignment of the Bonus Make a Difference?}

The Coase Theorem offers a definite prediction for the outcome of the Illinois experiment: In the absence of transaction costs, the initial assignment of the payment to the worker or to the employer should not affect the efficiency of the employment contracts, the allocation of resources (in terms of the number of workers hired and the number of bonuses paid), or the distribution of income between employers and employees. I will refer to this special case (in which changing entitlements are predicted to have no effect on efficiency, allocation, or distribution) as the Coasean "identity prediction."

\section{A. Transaction Costs}

The three elements of the identity prediction apply only in the idealized world of zero transaction costs. Although transaction costs in the Illinois experiment were not zero, there are reasons to believe that they were relatively low. ${ }^{16}$ Specifically, three aspects of this experiment (the number of

12. New unemployment compensation claimants who qualified for the experiment were randomly assigned to one of these three groups based on the last two digits of their Social Security number. To qualify for the experiment, an individual had to (1) file an initial claim for unemployment compensation between July 29, 1984, and November 17, 1984; (2) be eligible for 26 weeks of unemployment insurance benefits; (3) register with one of $22 \mathrm{Job}$ Service offices in northern and central Illinois; and (4) be between 20 and 54 years of age. In addition, claimants excluded from the experiment were those on layoff with a definite recall date within four weeks, recently separated veterans or Federal employees, and members of registered unions who obtain work through hiring halls. R. Spiegelman \& S. Woodbury, Final Report, supra note 11, at 2.1.

13. Since the hiring prospects of EPG workers could be improved only if the workers themselves informed potential employers of the existence of the bonus, members of the EPG were also given a packet of letters of introduction that explained the bonus scheme to prospective employers. R. Spiegelman \& S. Woodbury, Final Report, supra note 11, at 3.4 .

14. Final Report, supra note 11, at app. A3.

15. For a more probing analysis of the issue of transaction costs in this experiment, see infra Section IV. 
actors involved, the nature of their relationship, and the condition of the labor market) indicate the presence of relatively low transaction costs.

The number of actors involved in a potential Coasean bargaining situation has been deemed critical to the emergence of an efficient outcome. ${ }^{16}$ On the one hand, too many actors can inhibit bargaining. A large number of actors may reduce the likelihood that an agreement will be reached. ${ }^{17}$ In such cases it is typically difficult for the parties to identify others with whom they might profitably bargain. Even if the other parties can be identified, the transaction costs associated with communicating and negotiating may be prohibitive. On the other hand, too few actors may also inhibit bargaining. Two is the optimal number of parties from the perspective of reducing the costs of coordination. But if the parties are locked in a bilateral monopoly, where neither party has alternatives to dealing with the other, transaction costs will be sharply elevated. In such cases there may be numerous possible Pareto-superior bargains, but the parties may not actually reach one of these outcomes without consuming considerable time and resources..$^{18}$ Moreover, if both of the parties are committed to capturing as much of the fixed prize as possible, the likelihood increases that no bargain will be achieved. ${ }^{19}$

The Coasean bargaining situation that was created in the Illinois experiment appears, however, to have offered the best of both worlds: there were only two parties who had to negotiate, and they were not locked into a bilateral monopoly. ${ }^{20}$ In any potential employment relationship, the worker and the employer necessarily come together to determine whether the relationship will be established. The existence of the bonus provides merely one additional piece of information about the value to both parties of entering the relationship. The only added burden it imposes is the need to determine how to split the bonus, if splitting the bonus should prove desirable. ${ }^{21}$ Moreover, rather than being locked together in a relationship

16. See R. Posner, Economic analysis of Law 54-55 (3d ed. 1986); P. Samuelson \& W. NordhaUs, ECONOMICS 719 (1985).

17. See Baumol, On Taxation and the Control of Externalities, 62 AM. ECoN. Rev. 307 (1982); Calabresi \& Melamed, Property Rules, Liability Rules, and Inalienability: One View of the Cathedral, 85 HARv. L. REv. 1089 (1972). Hoffman and Spitzer, however, present experimental results in which Coasean outcomes are obtained with "groups of twenty persons or fewer, when bargaining, coordination, and enforcement costs are low and there are few information problems." Hoffman \& Spitzer, Large Bargaining Groups, supra note 8, at 171.

18. Kenneth Arrow has noted that a trading problem arises if there is "only one buyer and one seller and no competitive forces to drive the two into competitive equilibrium." Arrow, The Organization of Economic Activity, in The Analysis and Evaluation of Public Expenditure: The PBB System, Vol. 1, JEC, 91st Congress, 1st Session, 47, 58 (1969). The classic illustration of bilateral monopoly in a legal setting is afforded by two opposing parties in litigation, who can deal only with each other in trying to settle their dispute. See R. PosNer, supra note 16, at 54, 523.

19. In any event, even if a bargain can be struck, the haggling of the parties over the fixed prize constitutes socially wasteful transaction costs. See R. POSNER, supra note 16, at 54-55.

20. Section IV infra provides a more exhaustive assessment of the potential bargaining problems present in this experiment.

21. The parties must also be able to make some judgment about the likelihood that the employment relationship will last for at least four months. If there is a positive probability that the job will 
in which one party can hold out in an attempt to extract any rents provided by the $\$ 500$ bonus, both parties are always free to look elsewhere if a salary offer is too low or a wage demand is too high. If an employee's wage demand would enhance the welfare of the employer, the employer will accept it or risk losing the employee to another potential employer. ${ }^{22}$ Hence, the problem of bilateral monopoly is mitigated. ${ }^{23}$

The condition of the labor market can affect the level of transaction costs. As Peter Howitt notes, transaction costs can rise and fall with the business cycle because the per-unit cost of transacting depends inversely on the amount of hiring activity in the market:

For example, a decrease in the demand for labor makes it harder to find a job as well as reducing the wage, because potential employers advertise less and become less willing to arrange interviews, read job applications, return calls, and so forth. From the potential employer's point of view, the labor market becomes less thin when the number of unemployed workers searching for jobs increases and the cost of finding suitable potential recruits thereby decreases. . . . The extra cost of dealing in a thin market is primarily that of identifying, contacting, and negotiating with a suitable trading partner. ${ }^{24}$

In other words, as the demand for labor increases, workers should more readily find employment since employers are interested in finding them. At the same time, transaction costs will be high from the perspective of the employer if relatively few workers are looking for jobs. One would therefore expect transaction costs to be at their lowest if the demand for labor were increasing rapidly as the economy pulled out of a deep recession. This was the condition of the Illinois economy at least at the begin-

have a shorter duration, then the expected value of the bonus will be less than $\$ 500$. In addition, the parties may have to confront the issue of enforcing an agreement to split the bonus.

22. If the eleven-week deadline were about to expire, a bilateral monopoly might arise since the time for additional job search would be drastically curtailed, thereby effectively eliminating the availability of other options. In such a case either the two parties would agree or no bargain would be reached. Nonetheless, the worker could avoid even this bilateral monopoly problem by not divulging her time constraint to the employer. Without this knowledge, the employer would not recognize or be able to exploit this potential monopoly power.

23. The Illinois experiment was designed to determine whether unemployed individuals receiving unemployment compensation take so long to return to work because of the small number of job offers that they receive or because of their inadequate job search efforts. See R. Spiegelman \& S. Woodbury, Final Report, supra note 11, at 1.2. Elements of the bilateral monopoly problem remained to the extent that the problem was due to limited job offers, since prospective employees may have had few viable options beyond an initial job offer. Such trading problems might arise if jobs are scarce and workers believe that their options are limited. Indeed, the fact that workers searching for jobs will generally accept their first job offer may suggest a situation closer to a one-buyer market (albeit many sellers) than to perfect competition. Clark \& Summers, Labor Market Dynamics and Unemployment: A Recansideration, 1 Brookings PAPERS ON ECONOMIC Acriviry 13, 55 (1979), note that only $10 \%$ of unemployed individuals in the special 1976 job-search survey reported rejecting a job offer.

24. Howit, Transaction Costs in the Theory of Unemployment, 75 AM. ECON. REv. 88, 90 (1985) (footnote omitted). 
ning of the bonus experiment in mid-1984. ${ }^{25}$ In sum, the condition of the Illinois economy helped to reduce transaction costs for participants in the bonus experiment: with numerous unemployed workers in Illinois, employers had an easy time finding recruits; at the same time, the increasing demand in the economy made employers more eager to look for workers.

\section{B. A Model of a Perfectly Competitive Labor Market}

Section A set forth a prima facie case for the proposition that transaction costs were relatively low in this experiment. This Section sets out the Coasean predictions for the results of the Illinois bonus experiment. These efficiency, invariance, and distributional predictions will then provide a framework for analyzing the actual data from the experiment in Part III.

A significant feature of the typical labor market is the existence of many buyers and sellers. ${ }^{26}$ The model of a perfectly competitive labor market is therefore often used to begin analyses of the effects of labormarket interventions, ${ }^{27}$ and I follow that convention here. In Section C, however, I relax a number of the stylized assumptions of the perfectly competitive market and set forth predictions concerning the Illinois experiment based on a bargaining model of unemployment. ${ }^{28}$

The existence of either bonus program would presumably increase the chance (vis-a-vis members of the control group) that members of the WPG or the EPG would find a job within the eleven-week cutoff period. ${ }^{28}$ Figure I, which depicts a perfectly competitive labor market, illustrates that the initial assignment of the potential $\$ 500$ bonus to the worker

25. The unemployment rate in Illinois was $11.4 \%$ in $1983,9.1 \%$ in 1984 , and $9.0 \%$ in 1985 . Transaction costs would have been even lower had the sharp fall in unemployment that occurred between 1983 and 1984 continued into 1985. Bureau of Labor Statistics, U.S. Dep'T OF Labor, Geographic Profile of Employment and Unemployment (1983-85).

26. Martin Weitzman has written that, "[a]t the level of an entire economy, no other commodity comes even close to being as substitutable as labor is across its various roles and functions. On this basis alone there would appear to be a strong $a$ priori case that the labor market should be essentially competitive." M. Weitzman, The Share Economy 28 (1984). Robert Frank notes:

[T] The logic of the competitive labor market model is . . . airtight. When the conditions of this model are met, its prediction that workers will be paid the respective value of their marginal products is unequivocal.

It is fair to say that economists as a group believe that these conditions are, for the most part, satisfied in practice. . . .

R. Frank, Choosing the Right Pond 41 (1985).

27. See P. Samuelson \& W. Nordhaus, supra note 16, at 613-23; R. LiPSEY, P. STEiner \& D. Purvis, Economics 358-59 (7th ed. 1984); R. Flanagan, L. Kahn, R. Smith \& R. EhrenBERG, ECONOMICS of tHe EMployment Relationship 38-43 (1989) [hereinafter Flanagan \& KAHN].

28. In addition, in Section IV(D) infra I also explore the effect of the Illinois experiment using a model incorporating a minimum-wage constraint.

29. Even if no bargaining were possible, EPG workers would become cheaper to employers, and therefore more of them should be hired; WPG workers would earn more from working, and therefore could be expected to pursue employment with greater vigor. If participation in the program stigmatizes the workers, however, the search for employment could be hindered. See infra Section IV(B)(3). 
(in the WPG) or to the employer (in the EPG) should yield identical outcomes.

\section{Figure I}

The Effect of the Two Bonus Schemes on the Supply and Demand of Labor

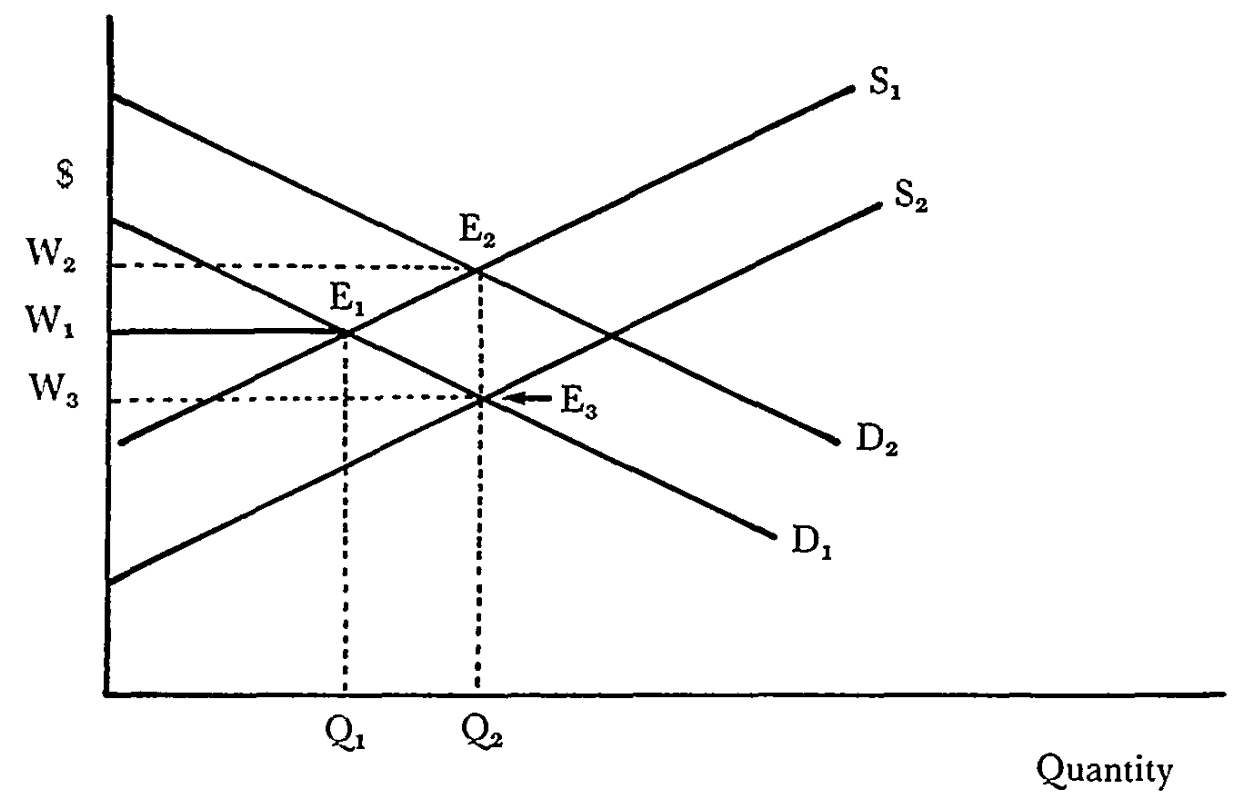

Let $D_{1}$ and $S_{1}$ represent the demand for and supply of labor in the absence of a bonus-incentive scheme. In this case, the resulting competitive equilibrium wage and quantity of labor are $W_{1}$ and $Q_{1}$. Now consider the effect of the two bonus schemes.

\section{Employer-Payment Scheme}

Under the employer-payment scheme the $\$ 500$ bonus makes the worker more attractive to the employer as modelled by the upward shift in the demand curve to $D_{2}$. The resulting intersection of $D_{2}$ and $S_{1}$ at $E_{2}$ gives the quantity of labor hired, $Q_{2}$. The wage paid by employers has now fallen from $W_{1}$ to $W_{3}$, and the wage received by workers has risen from $W_{1}$ to $W_{2}$. The difference between $W_{3}$ and $W_{2}$ represents the government's contribution to the hiring, which has the effect of increasing the number of workers hired from $Q_{1}$ to $Q_{2}$.

\section{Worker-Payment Scheme}

Under the worker-payment scheme the $\$ 500$ bonus makes working more attractive to the worker. In other words, the disutility associated with working for a given wage has been reduced because the worker will 
receive an additional payment of $\$ 500$. This decreased cost of (or added benefit from) working can therefore be modelled as a downward shift in the supply curve from $S_{1}$ to $S_{2}$. The resulting intersection of $D_{1}$ and $S_{2}$ at $\mathrm{E}_{3}$ gives the quantity of labor hired, $\mathrm{Q}_{2}$. Since the upward shift in the demand curve under the employer-payment scheme has the same effect as the downward shift in the supply curve under the worker-payment scheme, the amount of labor hired under the two schemes is identical. Similarly, the amount paid by the employer, $\mathrm{W}_{3}$, and the amount received by the worker, $\mathrm{W}_{2}$, will be identical under the two schemes. ${ }^{30}$

Figure I illustrates all three elements of the Coasean identity prediction: the efficiency prediction, the invariance prediction, and the distribution prediction. First, following standard microeconomic theory, the efficient outcome is given by the intersection of the supply and demand curves, assuming that the curves fully embody social costs and benefits. Since under either bonus scheme the equilibrium outcome will occur where the appropriate supply and demand curves intersect, the outcome will necessarily be efficient, as the Coase Theorem predicts. Second, Figure I shows that the amount of labor hired will be the same, $Q_{2}$, under either assignment of the right to the bonus. Third, the assignment of the bonus to either the worker or the employer, when the two are in a contractual relationship, should not affect the ultimate earnings of either group. In both cases employers will pay $\mathrm{W}_{3}$ in order to hire labor, and the workers will receive wages $\mathrm{W}_{2}=\mathrm{W}_{3}+\$ 500 .^{31}$

The above analysis demonstrates that, in a Coasean world of perfect competition and zero transaction costs, the expectation that the employerpayment scheme would modify only the behavior of employers while the worker-payment bonus would modify only the behavior of WPG workers is incorrect. ${ }^{32}$ Perhaps this expectation about the effects of the two bonus schemes stems from the misconception that the initial recipient of a government benefit or the initial bearer of a government burden will be the ultimate beneficiary or bearer. In a perfectly competitive market economy this is often not the case. For example, while the tax-free status of municipal bonds might at first appear to benefit those who buy them, the municipality is both the intended and the actual beneficiary because it will be

30. Harold Demsetz used a similar analysis to demonstrate that the equilibrium level of employment as well as the distribution of wealth between workers and firms should be unaffected by a requirement that employers compensate workers for costs arising from industrial accidents. The changing legal rule simply generates offsetting alterations in wages, if all parties have perfect information. Demsetz, Wealth Distribution and the Ownership of Rights, $1 \mathrm{~J}$. LEGAL STud. 223, 224-27 (1972).

31. Note that while the distribution of income is unaffected by the changing legal standard in this case, this is not universally true, even if the invariance thesis holds. See supra note 3.

32. This was the explicit belief of the directors of the Illinois experiment, who state that the purpose of the experiment was "to compare the benefits of offering bonuses to employers (thus affecting the demand for labor) with the benefits of offering them to claimants (and thus affecting the supply of labor)." R. Spiegelman \& S. Woodbury, Final Report, supra note 11, at 1.2. 
allowed to borrow at a lower cost. ${ }^{33}$ Similarly, when Congress sought to encourage minority ownership of broadcast stations, it empowered the Federal Communications Commission to issue tax breaks to those who sold stations to minority purchasers, instead of authorizing the Commission to give tax breaks directly to the purchasers. ${ }^{34}$ As another example, when Congress provides for a social security tax on wage and salary earnings, the same amount of tax revenue should be collected and the same number of employees should be hired, regardless of whether the tax is imposed on the employer or the employee ${ }^{35}$ In these cases, the true incidence of the government tax or transfer depends upon the underlying supply and demand elasticities, and not upon which party pays the tax or receives the benefit in the first instance.

\section{A Bargaining Model of the Employment Process}

The above analysis demonstrates that, if the government were to offer monetary inducements to encourage employment, it should not matter in terms of efficiency, employment levels, or distribution whether the bonus is paid to the employer or to the employee. The wage will simply adjust to reflect the greater benefit from establishing the employment relationship. The market will determine how the bonus is distributed, and there will be no need for extended bargaining between the parties.

The situation presented in the Illinois experiment, however, was somewhat different from the case of monetary inducements universally known to be offered for all new hirings. First, in the experiment only the worker initially knew of the bonus. If the worker chose not to mention the bonus, potential employers would have no knowledge of it. To benefit from the bonus, the worker must have informed his employer of its existence and then explicitly bargained over its distribution. Thus the informational advantages of a competitive market that inform employers and workers of

33. If the increased demand for the bonds drives the interest rate paid by the municipality down to the after-tax interest rate available on other bonds of similar risk, the municipality will garner all the benefit from the legislative initiative.

34. The Internal Revenue Code provides that the FCC can permit sellers of broadcast stations to defer the payment of capital gains taxes when the sale is deemed to effectuate an FCC policy. 26 U.S.C. \$ 1071 (1954); see also Federal Communications Commission, Rexamination of the Commission's Camparative Licensing, Distress Sales and Tax Certificate Policies Premised on Racial, Ethnic, or Gender Classifications, 3 FCC REC. 766 (1988) (announcing the FCC policy of fostering minority ownership of broadcast stations).

35. While there is no economic difference between these two cases in competitive labor markets, there may well be a politically significant difference. Thus, Congress has provided that in 1988 employees and employers must each pay $7.51 \%$ of their initial earnings, for a combined social security tax of $15.02 \%$ of the wage bill. For self-employed individuals, who are both employers and employees, the social security tax is only $12.12 \%$. This is defended on the erroneous rationale that the selfemployed should not pay as large a tax because they have no employer to shoulder some of the burden. The Federal Government pays the remaining $2.90 \%$ for the self-employed out of general revenues. Bureau of the Census, U.S. DeP'T of Commerce, Statistical abstracts of the U.S. (1986). 
the market wage were absent under both bonus schemes. ${ }^{36}$ Second, the analysis in Section B implicitly assumes that the bonus scheme was open to all employers or to all employees, when in fact the scheme was open to only a small fraction of workers and their employers. ${ }^{37}$ Third, the basic model depicted in Figure I assumes that the market clears; that is, everyone who wants a job at the current wage finds one. In other words, while there may be plenty of voluntary unemployment in the world depicted in Figure $I$, it does not admit the possibility of involuntary unemployment. ${ }^{38}$ This could conceivably be a major shortcoming since the model implicitly assumes the answer to one of the questions the Illinois experiment was intended to explore: Do unemployed workers remain on the compensation rolls because they are unwilling to take a job at the current wage or because no work is immediately available at the current wage?

These complications are largely overcome in the following bargaining model in which only employees are deemed to have knowledge of the bonus scheme and in which involuntary unemployment exists because it takes time for unemployed workers to become matched with employers with suitable job vacancies. ${ }^{30}$ The following analysis examines whether these factors undermine the identity prediction, which held true in the context of the perfectly competitive labor market. ${ }^{40}$

\section{The Efficiency and Invariance Predictions}

Consider the situation of a worker who has just been laid off from work and who applies for unemployment compensation. The worker will evaluate her job opportunities as well as the option of not working at all, the latter option entitling the applicant to receive unemployment compensation for a total of twenty-six weeks. ${ }^{41}$ The worker will then select the option with the highest present value. To simplify the analysis, at first

36. To use an example discussed above, consider the case of a tax-free municipal bond. Since these bonds trade in competitive financial markets, no bargaining over the price of the bond is necessary or, for that matter, possible. A buyer merely calls a broker to ascertain the competitively determined price, which fully incorporates the benefit of the tax subsidy. The model in Section II(B) supra implicitly assumes that the labor market operates as competitively as a financial market and therefore that the market determined the value of the bonus scheme to workers and employers.

37. The 8000 EPG and WPG workers represented only one-tenth of one percent of the total labor force in Illinois at the time of the experiment.

38. Voluntary unemployment exists when a worker is able to secure work at the going wage but chooses not to. Involuntary unemployment occurs when a worker is willing to work at the going wage but cannot find a job. See Flanagan \& KaHN, supra note 27, at 576-77.

39. I explicitly model the case in which involuntary unemployment arises from a minimum-wage law in Section IV(D) infra.

40. For a discussion of how labor markets diverge from the simple competitive model, see Williamson, Wachter \& Harris, Understanding the Employment Relation: The Analysis of Idiosyncratic Exchange, 6 BELL J. Econ. 250 (1975).

41. Unemployment compensation schemes typically require recipients to search for employment or to risk termination of their benefits. In practice, however, a worker who is not interested in finding a job-that is, has chosen leisure as a preferred option-will be able to accommodate this preference. Indeed, if the state could cheaply monitor unemployment recipients to ensure that they were diligently searching for work, there would be no need for a bonus scheme. 
assume that there are only three variables that will influence this outcome: $W_{\mathrm{i}}$, which represents the wage on the job; ${ }^{42} M P_{i}$, which represents the value of the marginal product of the worker on the job; ${ }^{43}$ and $V_{u c}$, which represents the value to the worker of remaining unemployed and collecting unemployment compensation. ${ }^{44}$ Since this initial simplified model assumes that the entire value of a job to a worker is captured in the wage, a mutually satisfactory employment relationship can be established if two conditions hold. Condition One: $\mathrm{MP}_{\mathrm{i}} \leq \mathrm{W}_{\mathrm{i}}$; that is, the worker will produce at least as much as she costs the employer; and Condition Two: $\mathrm{W}_{\mathrm{i}}$ $\leq \mathrm{V}_{\mathrm{uc}}$; that is, the worker will gain at least as much by working as she does by remaining unemployed. If either of these conditions fails, the worker will not be hired in job i, because either the employer will not want her or the worker will prefer to remain unemployed. ${ }^{45}$

The ostensible purpose of the Illinois experiment was to determine whether incentive payments could reduce the cost of state unemployment compensation expenses and whether payments to workers or to employers would be more effective in achieving this goal. Those conducting the study assumed that if unemployment recipients remained unemployed primarily because they were not sufficiently attractive to employers-a violation of Condition One-then the solution would be to provide a bonus to employers. On the other hand, if unemployment recipients remained unemployed primarily because they found unemployment more attractive than work-a violation of Condition Two-then the solution would be to provide a bonus to the workers. By comparing the results from the two programs, it was thought that one could identify which condition was more often violated. In a Coasean world of costless and unrestricted bargaining, however, this would not be the case.

Figure II depicts all the possible cases in which Conditions One and Two are or are not violated.

42. Assume further that the labor contracts are for a fixed duration of at least four months and that the wage refers to the worker's compensation over this entire period. With no loss in generality, this assumption simplifies the analysis by avoiding the need to convert a one-time bonus into an annual time-flow benefit based on the expected duration of employment.

43. By hiring an extra worker, an employer expects to be able to increase production and therefore to earn higher revenue. The dollar value of the increased production attributed to the last worker hired is the worker's marginal product. P. SAmuelson \& W. Nordhaus, supra note 16, at 581.

44. Since $W_{i}$ is the only variable representing the benefit to a worker of having job $i$, we are assuming, merely for simplicity, that there are no nonmonetary factors that influence the worker's preference between available job options. This assumption is relaxed infra note 48 . On the other hand, $V_{u c}$ embodies the total benefits-monetary and nonmonetary-derived from not working. Nonmonetary benefits can include the value of leisure or of pursuing other activities preempted by work. Monetary benefits include the value of unemployment compensation, the possible higher expected wage from continued job search, or the pecuniary returns from investing in additional education.

45. If the worker can earn a higher wage in job $n$ than in job $i$, then he or she may not wish to work in job $\mathrm{i}$ even if the two conditions hold. In that event, both conditions will also hold for job $\mathrm{n}$, and the analysis can proceed with reference to that job with no loss in generality. 
Figure II

Valuations of An Employer-Worker Match in Job i:

Four Cases Comparing the Worker's Marginal Product, the Wage, and the Value of Remaining Unemployed

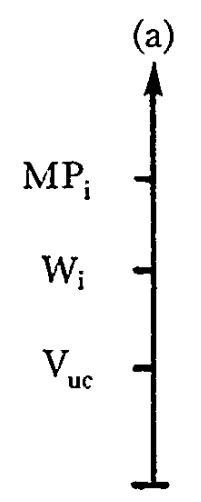

(c)

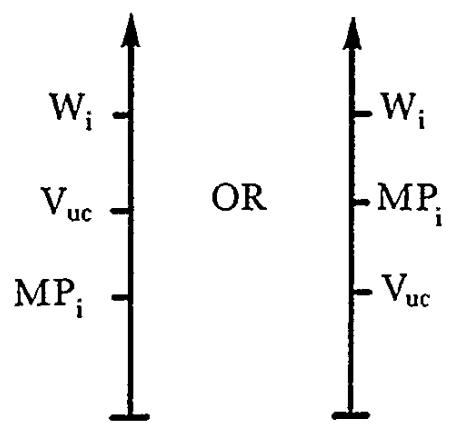

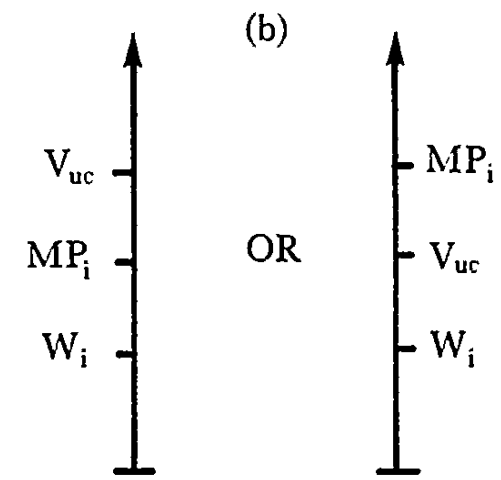

(d)

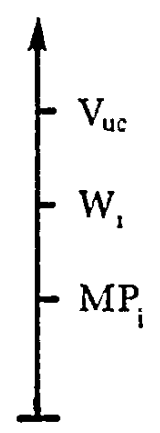

The following analysis of each case demonstrates that workers' experiences in obtaining employment should be identical, whether the workers are in the EPG or the WPG.

\section{a. Both conditions hold $\left(M P_{i}>W_{i}\right.$ and $\left.W_{i}>V_{\mathrm{uc}}\right)$}

In this case, the worker is able to find a satisfactory job whether or not the bonus scheme exists. The introduction of either bonus payment scheme therefore does not change the employment experience of workers who fall in this category, although one or both of the parties receives a total of $\$ 500$ in rents. In other words, the state is simply providing a bonus without obtaining any benefit. 


\section{b. Only Condition One Holds $\left(M P_{i}>W_{i}\right.$, but $\left.W_{i}<V_{u c}\right)$}

In this event, the worker wishes to remain unemployed in the absence of a bonus incentive, since $\mathrm{V}_{\mathrm{uc}}>\mathrm{W}_{\mathrm{i}}$. Whether any $\$ 500$ bonus scheme can be successful in inducing the worker to take a job depends on the distance between $\mathrm{W}_{\mathrm{i}}$ and $\mathrm{V}_{\mathrm{uc}}$. If $\mathrm{V}_{\mathrm{uc}}-\mathrm{W}_{\mathrm{i}}>\$ 500$, then neither bonus scheme will alter the worker's preference for unemployment. Even if the worker captures the entire bonus, he would still be worse off working than remaining unemployed. Only when $V_{u c}-W_{i}<\$ 500$ is the bonus scheme potentially effective. But a comparison of the results under the worker-payment and employer-payment schemes reveals that neither bonus alters the employment decision of either party when $\mathrm{V}_{\mathrm{uc}}-\mathrm{W}_{\mathrm{i}}<$ $\$ 500$.

Under the worker-payment scheme, the employer is already willing to hire the worker for job $i$, so there is no need for the worker to offer any of the bonus to the employer. Therefore, by taking the job, the worker can earn $\mathrm{W}_{\mathrm{i}}+\$ 500>\mathrm{V}_{\mathrm{uc}}$. Accordingly, he will take the job. ${ }^{46}$

Under the employer-payment scheme, the worker is not willing to take job $\mathrm{i}$ unless he receives at least $\mathrm{V}_{\mathrm{uc}}-\mathrm{W}_{\mathrm{i}}$ in additional payments. But since the employer is willing to hire the worker even in the absence of any bonus (because $M P_{i}>W_{i}$ ), the employer is willing to pay the $V_{u c}-W_{i}$ out of the $\$ 500$ bonus. Even if the employer gives up all the bonus, he is still better off than he would be not hiring the worker. Thus, under either payment scheme, the worker will be hired if and only if the vertical distance between $V_{u c}$ and $W_{i}$ in Figure $\mathrm{II}(\mathrm{b})$ is less than $\$ 500 .{ }^{47}$ One might think of the bonus in this case as a bribe on the part of the state of Illinois to encourage the worker to leave the unemployment rolls.

In summary, even though $V_{u c}>W_{i}$, the existence of the bonus (regardless of to whom it is initially assigned) will ensure that a mutually beneficial employment contract can be reached as long as the difference between $\mathrm{V}_{\mathrm{uc}}$ and $\mathrm{W}_{\mathrm{i}}$ does not exceed $\$ 500$. If $\mathrm{V}_{\mathrm{uc}}$ and $\mathrm{W}_{\mathrm{i}}$ are separated by more than $\$ 500$, the bonus scheme will not influence the employment/

46. If the employer knew that the employee would be entitled to a bonus, he might try to hold out to get some of it for himself. Such strategic behavior is unlikely to be effective to the extent that the worker has other potential job options. Furthermore, the problem would be minimized in this experiment because only the worker would know of his entitlement to the bonus. In many cases, the worker might be able to avoid revealing this information until it became obvious that he would not be hired unless he were willing to share some of his bonus. On the other hand, the information might have to be conveyed on an employment application if the opportunity to bargain were to become a realistic option.

47. This analysis has implicitly assumed that the bonus will be obtained with certainty. To accaunt for the probability that the employment relationship will terminate prior to four months, one can simply think of the bonus as being the expected value of receiving $\$ 500$. While this complication implies that the bonus scheme will be less effective because it reduces the attractiveness of the bonus for risk-neutral parties, it will not alter the conclusions of the analysis, even if the parties have different expectations of the probability of premature termination. Section IV(B)(2) infra discusses related issues concerning the effect of differential tax treatment. 
leisure choice, either because the worker always works $\left(\mathrm{W}_{\mathrm{i}}>\mathrm{V}_{\mathrm{uc}}\right)$ or because he always remains unemployed $\left(\mathrm{V}_{\mathrm{uc}}>\mathrm{W}_{\mathrm{i}}+\$ 500\right)$.

\section{c. Only Condition Two Holds $\left(W_{i}>V_{u c}\right.$ but $\left.M P_{i}<W_{i}\right)$}

In this case, the worker is willing to work at job $\mathrm{i}$, but absent a bonus the employer is not willing to hire her because $M P_{i}$ falls below $W_{i}$. If $W_{i}-M P_{i}>\$ 500$, then neither bonus scheme is sufficient to induce the employer to hire the worker. Even if the employer could capture the entire bonus, she would lose money by hiring the worker. On the other hand, if $W_{i}-M_{i}<\$ 500$, then the possibility of a mutually beneficial employment contract exists under either scheme.

Under the employer-payment scheme, if the employer keeps the entire $\$ 500$ bonus, she is glad to hire the worker because she is then paying $\mathrm{W}_{\mathrm{i}}-\$ 500<M \mathrm{P}_{\mathrm{i}}$ to receive output valued at $M \mathrm{P}_{\mathrm{i}}$. Since the worker is better off vis-a-vis unemployment even if she receives none of the bonus, the bargain should be struck.

Since the worker is better off working than not working under the worker-payment scheme, she has an incentive to offer some of the bonus to the employer. As long as the side payment to the employer is enough to push the value to the employer of hiring the worker above $W_{i}$, then the employer will be willing to hire the worker. Since the $\$ 500$ bonus provides the worker with sufficient funds to make the necessary side payment, again the employment bargain will be struck.

\section{d. Neither Condition Holds $\left(M P_{i}<W_{i}\right.$ and $\left.W_{i}<V_{u c}\right)$}

In this event, both parties must receive enough money from the bonus to raise their respective benefits from the employment relationship above the accompanying costs. This cannot be accomplished unless the following condition applies: Condition Three: $\left(\mathrm{W}_{\mathrm{i}}-\mathrm{MP}_{\mathrm{i}}\right)+\left(\mathrm{V}_{\mathrm{uc}}-\mathrm{W}_{\mathrm{i}}\right)<\$ 500$. If Condition Three is not met, then neither bonus payment scheme will be able to induce the hiring. If the condition is met, however, we are in precisely the same position that we saw above. Regardless of who initially receives the payment, it will be to both parties' advantage to share the bonus in such a way that they earn more by establishing an employment relationship than by not doing so. ${ }^{48}$ Again, one can think of the bonus as a

48. Condition Three is based on the assumption that the wage reflects the entire value of the job to the worker. See supra note 44 . The analysis in the text can be altered to account for the case in which the value of the job to the worker-call it $V W_{i}-$ is different from the monetary wage, $W_{i}$, owing to the existence of nonpecuniary considerations. In this event, one can simply substitute the worker's valuation $\mathrm{VW}_{\mathrm{i}}$ for $\mathrm{W}_{\mathrm{i}}$ in the second parenthetical term of Condition Three. The conclusion remains the same: if the $\$ 500$ bonus is sufficient to induce both parties to establish an employment relationship, they will do so, regardless of who receives the bonus from the state.

One can also complicate the model by assuming that employers offer a fixed wage $W_{i}$ and then search for the best worker to fill the job. In this case, the marginal product of the worker on the bonus scheme may be less than that of some alternative worker, but the bonus-worker will be hired when- 
bribe by the state of Illinois to encourage the hiring, and if Condition Three holds, the bribe will be sufficient regardless of which party receives the check from the state. ${ }^{49}$

Accordingly, any time working is the highest-valued use for a particular EPG or WPG worker, costless bargaining will ensure that both parties will be better off if the worker is hired. Also, a rational worker will always be interested in using the bonus either to assist in getting a job or to enhance his or her earnings. Thus there is an informational asymmetry between employers and workers because potential employers will not be aware of the possible bonuses unless they are informed about them by the job applicants. Yet this asymmetry, absent transaction costs, should not prevent the fulfillment of the identity prediction. The worker will always

ever the $\$ 500$ payment is sufficient to encourage both the bonus-worker to work and the employer to forego the more productive worker. Note that in such a case the dollar wage of hiring the bonus worker will be $W_{i}$, but the economic wage will be the foregone marginal product of the more productive worker-that is, the opportunity cost.

While this example illustrates a potential inefficiency from this program in that it may induce the hiring of a less productive worker, there is a possible offsetting efficiency gain if the hired worker would otherwise have remained on unemployment compensation because of the leisure subsidy. As we know from the theory of the second best, it is at least possible that two departures from the conditions of overall efficiency would be preferable to only one such departure. See generally Lipsey \& Lancaster, The General Theory of the Second Best, 24 REv. Econ. STud. 11 (1957) (if one Pareto-optimal condition cannot be achieved, second-best optimum requires departure from all other Pareto-optimal conditions).

49. The metaphor of the bribe is applicable in a number of other settings. One can think of the tax-free status of municipal bonds as a bribe by the Federal Government to encourage investors to purchase these securities. Similarly, one might use bribes to encourage litigants to settle their cases rather than trying them. Indeed, litigation costs serve as just such an inducement. The above analysis has shown that the "bribing" effect of such costs is independent of which party will incur the costs at trial. The greater the total litigation costs, the greater will be the incentive for settlement, and the efficient outcome will be reached (assuming the bilateral monopoly problems can be overcome) regardless of how these litigation costs would have been divided between the parties at trial. In other words, the same rate of settlement will be observed whether the plaintiff incurs $\$ 2000$ in litigation costs and the defendant incurs $\$ 3000$, or the plaintiff incurs $\$ 3000$ and the defendant $\$ 2000$.

This can be shown formally using a litigation model set forth by Judge Posner for the "American system" in which both parties bear their own litigation expenses. R. POSNER, supra note 16 , at 524 . If $\mathrm{J}$ is the size of the judgment should the plaintiff win, let $\mathrm{P}_{\mathrm{p}}$ be the probability of the plaintiffs winning as estimated by the plaintiff, let $P_{d}$ be the defendant's estimate of that probability, and let $C_{p}$ and $C_{d}$ be the respective costs of litigation of the plaintiff and defendant. Litigation will occur only if: (1) $P_{p} J-C_{p}>P_{d} J+C_{d}$. If equation (1) does not hold, the parties will settle their dispute. Equation (1) can be rewritten as: (2) $\left(P_{p}-P_{d}\right) J>C_{p}+C_{d}$. As long as the sum of $C_{p}$ and $C_{d}$ in equation (2) remains unchanged, a shift in the expense from one party to the other will not alter the litigation rate.

Interestingly, this discussion does not imply that a law compelling the losing party in litigation to pay the winning party's attorney's fees-the "British system"-would have no effect on the settlement rate. For excellent discussions of this conceptually distinct problem, see R. POSNER, supra note 16, at 537-40, and Shavell, Suit, Settlement, and Trial: A Theoretical Analysis Under Alternative Methods for the Allocation of Legal Costs, 11 J. LEGAL. STud. 55 (1982) (settlement rates will be lower under rules shifting total cost of litigation to losing party).

My point is that in either the British or American systems the inducement to settle will depend only upon the combined size of the litigation costs of both parties, not on the division of these costs between the parties when incurred at trial. Posner and Shavell have shown that the movement from one system to the other will affect the settlement rate. The rationale behind their result is as follows: (1) optimism on the part of both parties to a dispute encourages litigation; and (2) optimistic parties will discount litigation costs under a rule that shifts costs to the prevailing party; therefore, (3) the inducement to settlement created by litigation costs is weakened under a cost-shifting rule. 
have an incentive to disclose the information whenever he or she has an opportunity to use the bonus to achieve a Pareto-superior outcome. ${ }^{\mathbf{S O}}$

\section{The Distribution Prediction}

The identity principle predicts invariance of outcomes in terms of efficiency, allocation, and distribution whenever the law allocates contract rights prior to the contract negotiations. ${ }^{51}$ But the identity principle does not operate when the law allocates the property rights that Coase discussed in his famous work. For example, it makes a considerable difference to landowners whether their neighbor has the right to burn toxic wastes so that they must bribe him to forego the polluting activity or whether the landowners have the right to be free from pollution so that the neighbor must bribe them to relinquish their right. Coase predicted that in the absence of transaction costs an efficient solution would be reached in both cases but that the two cases would differ in terms of the distribution of income. ${ }^{52}$ The reason for the different distributional consequences is that the assignment of the property right creates wealth in one party, who must then be compensated if he is to relinquish the right.

A very different situation existed in the Illinois experiment, however, since no wealth was created until the contractual agreement had been reached. ${ }^{53}$ The bonus simply represents a potential gain from contracting that both sides will try to capture. If both parties know of its existence, then regardless of the nominal assignment of the bonus to either employers or workers, the bonus will add $\$ 500$ to the total benefit available if the parties enter a contractual relationship. The respective bargaining skills,

50. To see this, imagine the situation in which $M P_{i}<W_{1}$, and $W_{i}>V_{u c}$, which implies that in the absence of any bonus the worker is willing to accept job $i$, but the employer is unwilling to hire her. If the bonus is sizable enough to induce the employer to hire the worker, the worker has an incentive to inform the employer of the bonus. This incentive is the same regardless of which payment group the worker is in: she must offer some portion of the bonus to the employer or she will not be hired, and the employer does not care whether the offered money comes from the worker (in the WPG) or from the state of Illinois (in the EPG). While efficient outcomes can at times be achieved without the worker's telling the employer of the existence of the bonus-for example, when the employer is already willing to hire the worker even without regard to the bonus-there is no case in this simple model in which the worker would gain by failing to disclose information about the bonus. See generally R. POSNER, supra note 16, at 526 ("the exchange of information is a normal incident of bargaining"). In Section IV, however, I do consider situations in which workers might want to avoid disclosing the existence of the bonus-for example, where applying for a job equipped with a bonus stigmatizes the worker.

51. To be more precise, the specified contractual right must either be a presumptive right that can be bargained away by the actions of the parties or a monetary right (such as a right to damages or, as in the Illinois experiment, to a certain payment) where the price of the bundle of rights is left open to negotiation by the parties.

52. In discussing his rancher/farmer example, Coase concluded that a shift in the legal entitlement "would not affect the allocation of resources but would . . . alter the distribution of income and wealth as between the cattle-raiser and the farmer." Coase, supra note 1, at 5 . But in his later worl: Coase suggests that the distribution of income would be unchanged in a world genuinely without transaction costs since through costless transacting the parties would have covered the contingency of a change in the legal rule. See supra note 3.

53. See supra note 4 . 
preferences, and economic conditions of the parties-and not the type of payment scheme-will determine how the total benefit from the employment relationship, including the $\$ 500$ bonus, will be divided.

While this conclusion may seem counter-intuitive, an example from another context may clarify the point. Attendance at a baseball game tends to be higher when a superstar pitcher is on the mound. It is a simple matter for such a player (or his agent) to ascertain how much additional revenue he brings to the club-owners from the enhanced ticket sales on days that he pitches. Clearly, though, the owner is the nominal holder of the entitlement to these increased revenues; after all, the fans pay the money to the owner, not to the pitcher. But if the superstar could take his skills to any team in baseball and generate similar increased ticket sales, the owner would have to share a hefty portion of the increased revenues with the pitcher. ${ }^{54}$ That the money is originally paid to the owner does not determine who gets to keep it (as between the owner and the pitcher). Similarly, that the state of Illinois pays the bonus to either workers or employers does not determine how the bonus money will be apportioned between the contracting parties.

\section{EXPERIMENTAL ResUlts}

We have seen that in the absence of transaction costs, the Coase Theorem predicts that the EPG and WPG groups should have reached identical, efficient outcomes. The empirical findings of the Illinois study, however, strongly contradict these theoretical predictions.

\section{A. Participation in and Use of the Bonus Schemes}

Before a bonus could be paid under this experiment, each member of the EPG and WPG had to make a number of decisions: (1) whether to agree to participate; (2) whether to try to use the bonus to secure employment; (3) whether to file the Notice of Hire (NOH) form if a job was obtained within eleven weeks; and (4) whether to file for a bonus if the job lasted at least four months. The different degrees of participation by the EPG and WPG workers (or their employers) at each of these four points stand out sharply in Table I. At every level workers were more interested in using the program if they, rather than their employers, were to receive the bonus. Members of the WPG manifested: (1) a greater willingness to sign the agreement to participate ( $84 \%$ for the WPG and only $65 \%$ for the EPG); (2) a greater willingness to try to use the bonus scheme once they had agreed to participate ( $93 \%$ for the WPG and only $66 \%$ for the EPG); ${ }^{\mathrm{sb}}$ (3) a higher submission rate of the NOH forms for

54. See generally R. LIPSEY, P. STFIneR \& D. PuRvis, supra note 27, at 342.

55. The figures for "active participants" are my projections based on results from the State of Illinois' telephone follow-up survey of 1006 EPG workers and 1000 WPG workers conducted at the 
those who "actively participated" (23.3\% for the WPG and only $11.7 \%$ for the EPG); and (4) a higher rate of receipt of the bonus for those who submitted the NOH (74.5\% for the WPG and only $56.3 \%$ for the EPG) ${ }^{86}$

Overall, the number of bonuses paid to WPG workers was almost five times the number paid to EPG employers. Clearly, the different amounts of bonus payments in the two groups was not solely the result of either the different rates of agreeing to participate or of actively participating. Even among only those who agreed to participate, WPG workers filed $\mathrm{NOH}$ forms at roughly three times the rate of EPG workers and received bonuses at almost four times the rate. If one focuses only on those who actively participated, the differentials narrow somewhat, but they are still substantial and statistically significant: WPG workers filed NOH forms at twice the rate and received bonuses at almost three times the rate as EPG employers. Workers obviously perceived these bonus schemes quite differently and responded much more favorably to the worker-bonus scheme. Because worker-payment and employer-payment bonuses would be equally efficient in a world of zero transaction costs, that more WPG workers than EPG employers received bonuses implies a violation of both the invariance and efficiency predictions of the Coase Theorem.

conclusion of the year-long program. Survey respondents who had signed an agreement to participate were deemed to have made no use of the program if, at the time of the telephone interview, they indicated that they (1) had not agreed to participate (although in fact they had agreed to participate); (2) did not remember whether they had agreed to participate; or (3) in the case of the EPG, did not tell any employer about the experiment. R. Spiegelman \& S. Woodbury, Final Report, supra note 11, at Tables 7-6 and 7-8. I use the term "active participants" to denote those who did not fall within these three categories.

One must interpret the results of the follow-up survey with caution. First, since this Survey was conducted in December 1985 and early January 1986, and the bonus experiment was initiated in July through November 1984, many individuals may simply have forgotten about events that occurred more than a year earlier. Second, the responses to the survey may not have been completely accurate. For example, EPG workers who were unable to get a job even with the assistance of the bonus might be reluctant to admit this fact and might simply prefer to state that they did not use the program. This does not seem to be an important factor, however, since the percentage of workers who agreed to participate but then stated they did not use the program was higher for those who found jobs quickly (41\%) than for those who did not $(31 \%)$. Id. This finding indicates that many EPG workers who were able to obtain a job quickly did not bother to try to use the bonus scheme, a fact which again suggests that these workers did not appreciate the possibility of capturing some of the $\$ 500$ bonus through bargaining.

56. The figures for the number of bonuses paid as a percentage of NOH forms submitted are somewhat imprecise. As Note 2 to Table I indicates, some employers and workers obtained bonuses without first submitting $\mathrm{NOH}$ forms. 
TABLE I

Participation In and Use of the Two Bonus Schemes

\begin{tabular}{|c|c|c|c|c|c|c|c|c|c|}
\hline \multirow[b]{3}{*}{$\mathrm{N}$} & \multicolumn{4}{|c|}{ EPG } & & \multicolumn{4}{|c|}{ WPG } \\
\hline & \multicolumn{4}{|c|}{ As \% of: } & & \multicolumn{4}{|c|}{ As \% of: } \\
\hline & Row 1 & Row 2 & Row 3 & Row 4 & $\mathbf{N}$ & Row 1 & Row 2 & Row 3 & Row 4 \\
\hline 3963 & 100.0 & - & - & - & 4186 & 100.0 & - & - & - \\
\hline 2586 & 65.3 & 100.0 & - & - & 3527 & 84.0 & 100.0 & - & - \\
\hline 1702 & 42.9 & 65.8 & 100.0 & - & 3284 & 78.5 & 93.1 & 100.0 & - \\
\hline 199 & 5.0 & 7.7 & 11.7 & 100.0 & 765 & 18.3 & 21.7 & 23.3 & 100.0 \\
\hline 112 & 2.8 & 4.3 & 6.6 & 56.3 & 570 & 13.6 & 16.2 & 17.4 & 74.5 \\
\hline
\end{tabular}

1. Total

Assigned

2. Agreed to

Participate

3. Active

Participant ${ }^{1}$

4.5

Source: R. Spiegelman \& S. Woodbury, supra note 11, at Table 7-6; Woodbury \& Spiegelman, Randomized Trials in Illinois, supra note 11, at Table 1; public use tapes.

Notes: 2The percentages of participants who are deemed "active" were obtained from the follow-up survey of 1000 workers from each group. These percentages were then applied to the population of those who signed the agreement to participate, yielding the projected figures of $\mathrm{N}$ in row 3.

2 These Final Report figures for the number of Notice of Hire forms submitted actually reflect both the number of those who submitted NOH forms and the number of those who obtained bonuses without submitting NOH forms.

${ }^{3}$ Note that 26 WPG workers and 6 EPG employers secured $\$ 500$ bonuses without filing an $\mathrm{NOH}$.

In all cases, the percentages for the EPG workers differ significantly from those for WPG workers. Specifically, one can always reject the hypothesis that these percentages are the same at the .01 confidence level.

Table I reveals that more than one in five WPG workers and almost three in five EPG workers refused to participate actively in the bonus program. ${ }^{67}$ Participation rates of less than $100 \%$ are not surprising for at least two reasons. First, some individuals have difficulty understanding such schemes and may shun them to avoid revealing their lack of comprehension. Second, workers who had abused or planned on abusing the unemployment compensation system-perhaps by arranging a false layoff or because they did not intend to search for work-might not want to invite the close scrutiny of their behavior that might accompany participation in such a program. For such individuals the expected value of program participation would be less than the anticipated costs, and the decision not to

57. The percentages of workers who actively participated are presented in the second column of Row 3 for each group. Of course, if $42.9 \%$ of EPG workers actively participated, then $57.1 \%$ of WPG workers (almost three in five) did not actively participate. 
participate would therefore be "efficient" from the worker's perspective. ${ }^{58}$ Yet efficient refusals would not seem to explain the difference between the participation rates of the two groups. If, as I argued in Part II, the expected benefits of both programs are the same, and we assume for the moment that the costs of using both programs were equivalent because transaction costs approached zero, then the different levels of participation must reflect inefficient decisions. ${ }^{50}$

If all EPG and WPG workers were invested with perfect foresight about their prospects in the labor market, then anyone who ultimately qualified for a bonus by obtaining a job of sufficient duration in a timely fashion, with or without the assistance of a bonus, should have received one. The reason is simple: the size of the pie to be split between employer and employee will be greater if the State of Illinois contributes $\$ 500$ to the transaction. Yet, although $25 \%$ of the WPG workers and $22.8 \%$ of the EPG workers satisfied the job requirements necessary to secure $\$ 500$ bonuses ${ }^{60}$ only $13.6 \%$ of the WPG workers and $2.8 \%$ of the EPG employers received them. In other words, bonuses were paid to only $54.5 \%$ of those eligible under the worker-payment scheme and only $12.4 \%$ of those eligible under the employer-payment scheme. ${ }^{61}$ While the lack of perfect foresight can explain why the percentage of bonuses received out of the population that ultimately qualified was substantially lower than $100 \%$, it fails to explain why this percentage was so different between the two groups.

Moreover, apparently inefficient behavior persisted even when participants were virtually certain they would be entitled to a bonus-for example, when all the employment and program requirements had already been met. Remarkably, as shown in Table II, a surprisingly large number of individuals met all the criteria for the payment of a bonus (agreeing to participate, filing an $\mathrm{NOH}$ after being hired within eleven weeks, and remaining on the job for four months) without ultimately receiving a $\$ 500$ bonus, because they simply failed to submit a voucher. Of the 553 WPG individuals who filed a clearly legitimate $\mathrm{NOH}^{62}$ and qualified for a bo-

58. Certainly, anyone who did not intend to return to the workforce and planned simply to collect unemployment compensation until the benefits were exhausted would have obtained no benefit from either payment scheme.

59. But see Part IV infra (discussing factors besides irrationality that might explain divergent results).

60. These figures refer to the workers who both obtained work within eleven weeks of initially filing for unemployment benefits and who remained on the job for four months. The corresponding percentage for the control group was $20.7 \%$. Woodbury \& Spiegelman, Randomized Trials in Illinois, supra note 11, at 525.

61. Id. "Eligibility" here implies that the worker satisfied the employment criteria for obtaining a bonus whether or not the necessary steps of program participation (such as agreeing to participate or filing a voucher to obtain an earned bonus) were taken.

62. The term "clearly legitimate NOH" needs clarification. Table II reveals that 193 EPG workers (or their employers) and 739 WPG workers filed NOH forms. Of these, not all, could be identified by the Illinois Department of Employment Security as having both left the unemployment compensation rolls and obtained employment within eleven weeks. There are a variety of reasons why this might be the case even though the worker did in fact secure employment within eleven weeks. These 
nus by remaining on the job for four months, only $82.5 \%$ actually received a bonus. Similarly, for the EPG, of the 140 clearly legitimate $\mathrm{NOH}$ forms that were filed by employers of workers who remained at work for four months, only $65.0 \%$ obtained a bonus. Overall, more than $20 \%(146 / 693)$ of fully earned bonuses-valued at $\$ 73,000$-were left unclaimed, and employers were considerably more lax than workers about claiming their bonuses. ${ }^{63}$ Since the final requirement for receipt of the bonus was simply to contact the Illinois authorities to pick up a check, the costs of receiving this money were quite small, presumably far less than $\$ 500 .^{64}$ The conclusion that a number of individuals and employers acted inefficiently is difficult to rebut. ${ }^{65}$

anomalies occur because the administrative records used in evaluating this experiment were designed to monitor the unemployment insurance system and not these bonus experiments. R. Spiegelman \& S. Woodbury, Final Report, supra note 11, at 4.11. To eliminate any ambiguities in the data, I limited my analysis in Table II to only those workers for whom the employment criteria had clearly been met. Therefore, of those who filed NOH forms, the subset of "clearly legitimate" forms is derived by limiting the sample to those identified by the Illinois administrative data as having both left the unemployment compensation rolls and having obtained employment within eleven weeks. My findings would be even more dramatic if I had used a more relaxed standard for identifying those participating workers who knowingly had fully qualified for a bonus.

63. Employers frequently do not avail themselves of government benefits to which they are entitled. As Lerman notes in discussing the effect of the targeted jobs tax credit, "It turns out that many firms do not claim credits that they could receive without any change in the workers they hire or in the wages they pay." Lerman, A Comparison of Employer and Worker Wage Subsidies, in JoBs For Disadvantaged WoRkers: The Economics of EMPloyment Subsidies 159, 177 (R. Haveman \& J. Palmer eds. 1982). In the an experiment in Dayton, Ohio, discussed infra note 117, Burtless noted "the high proportion of employers who failed to request payment of wage subsidies. Of the 70 voucher holders who found employment, only 19 , or little better than one-quarter, worked for firms that requested certification for wage subsidies." Burtless, Are Targeted Wage Subsidies Harmful? Evidence From a Wage Voucher Experiment, 39 InDus. \& LAB. REL. REv. 105, 112-13 (1985). The paperwork involved in the Dayton Study was considerably greater than that involved in the Illinois experiment. Firms had to document the earnings of the covered workers every three months, $i d$. at 108 , rather than just once having to document employment, as in the Illinois experiment. The low rate of use of the benefits payable to employers in the Dayton study was particularly striking when hiring a covered worker entitled an employer to receive a tax credit rather than the straight cash subsidy of the Illinois experiment. Again this suggests the added complexity of tax-credit vouchers as opposed to simple checks.

64. Nonetheless, the costs to an employer of remembering that the firm was entitled to a $\$ 500$ bonus after four months might be considerably higher than the cost of requesting an earned bonus.

65. Professor Ellickson, in his response to this article, opines at length that the failure to collect earned bonuses is readily explained by high transaction costs. Ellickson, The Case for Coase and Against Coaseanism, 99 YALE L.J. 611 (1989). He emphasizes the great burden of obtaining the employer's signature on the Notice of Hire form and the high costs of stigma in so doing. But these considerations are irrelevant, since the costs that Professor Ellickson alludes to had already been paid. All the workers I am referring to here had already filed NOH forms, thereby incurring the transaction and stigmatization costs, and had already earned their bonuses, thereby eliminating the contingent feature of the bonus. In fact, to the extent that Ellickson is correct that these costs were high, one would expect an increased likelihood that these workers would remember to file for their bonuses. I doubt that it costs $\$ 500$ to secure an employer's signature on a pre-printed form and then to mail the form in. 


\section{TABLE II}

The Number of Vouchers Paid When Workers Had Qualified Fully for Bonuses

Traits

1. Filed NOH:

2. Trait (1) and NOH Was Legitimate:

3. Trait (2) and Qualified For Bonus: Number:

$\%$ of Legitimate $\mathrm{NOH}$ filers:

4. Trait (3) and Bonus Was Paid:

Number:

$\%$ of Legitimate $\mathrm{NOH}$ filers:

$\%$ of Qualified:

$\begin{array}{ll}\frac{E P G}{193} & \frac{W P G}{739} \\ 172 & 630 \\ & \\ 140 & 553 \\ 81.4 & 87.8^{*} \\ & \\ 91 & 456 \\ 52.9 & 72.4^{* *} \\ 65.0 & 82.5^{* *}\end{array}$

Source: Author's calculations from the public use tapes.

Notes: Twenty-one EPG employers and 109 WPG workers filed NOH forms even though the Illinois Department of Employment Security records did not clearly indicate that the worker had met the employment requirements of leaving the unemployment rolls and obtaining employment within 11 weeks. I consider an NOH to be "legitimate" if the Illinois administrative records confirm that the worker did meet these initial employment criteria. If the worker then continued to work for four months, then she "qualified for a bonus."

In all cases, the percentages for EPG workers differ significantly from those for WPG workers. Specifically, one can always reject the hypothesis that these percentages are the same at either the .01 ("**") or .05 ("*") confidence level.

The number of workers and employers who fully qualified for bonuses but did not claim them is simply the number with trait (3) minus the number with trait (4). Thus, 140 EPG bonuses were fully earned by employers who filed NOH forms, but 49 (that is, 140-91) of these employers never requested and therefore never received their bonuses. Similarly, 97 (that is, 553-446) WPG workers passed up bonuses they had already earned.

Why the WPG and EPG performed so differently in terms of rate of participation and number of bonus payouts is not entirely clear, although some of the expressed reasons were decidedly "un-Coasean." low-up survey a number of EPG workers indicated they did not agree to participate because they opposed the notion that an employer should receive a bonus for hiring them. While the costs of using the employerpayment scheme were undoubtedly higher than those of using the workerpayment scheme because of the need to inform employers of the bonus, the likelihood that a rational cost-benefit analysis motivated all the results in Table I and especially Table II seems remote. Indeed, the most plausible

66. What does it mean to be "un-Coasean"? An example may help to illustrate my use of the term. A woman arrives at a movie theater to learn that the man in front of her has just purchased the last ticket to the show that she desperately wanted to see that evening. Realizing that her unusually strong subjective preference for seeing the movie makes it likely that she "values" seeing the movie more than the man does, the woman-in true Coasean fashion-offers to pay the man $\$ 20$ over the ticket price for the last ticket. Assume further that the $\$ 20$ would enable the man to have a frce meal at his favorite restaurant, which he prefers to attending the movie. If the man rejects the offered sum because he finds it "insulting" to be offered money or because he feels that the woman is trying to obtain something to which she does not have a right, then he is acting in an un-Coasean fashion. UnCoasean behavior does not necessarily imply irrationality, however. The man might well feel that his image as a movie lover would be compromised by accepting money to relinquish his ticket. 
explanation for the differences reflected in Table I may be that a large number of workers did not understand that both programs could increase their likelihood of getting a job quickly and that both programs could lead to the worker's receiving at least some portion of the $\$ 500$ bonus. ${ }^{67}$ For example, an EPG worker who was quite confident of his ability to obtain a job within eleven weeks but who failed to realize that through bargaining he could gain some or all of the $\$ 500$ bonus would perceive no value (apart from possible ingratiation) in the employer-bonus scheme. This erroneous perception doubtless contributed to the fact that almost ninety percent of the employers of EPG workers who satisfied the employment criteria ultimately failed to receive a bonus.

\section{B. Effect of the Bonus Schemes on Employment}

Section A explored the validity of the Coasean identity prediction by examining the program involvement and bonus performance of members of the EPG and WPG, as measured by the percentages of workers (or their employers) who ultimately received bonuses after agreeing to participate in the program, submitting Notices of Hire to the state agency, and filing vouchers. The next two sections further evaluate the Coasean identity prediction by examining the variables that most interested those conducting the Illinois experiment: the period of time that workers in the three groups continued to collect unemployment insurance and the amount of money collected. Once again, the findings that the WPG enjoyed greater improvements in obtaining employment ${ }^{\mathbf{6 8}}$ and that there were sig-

67. The failure to perceive the potential value that can be achieved through bargaining under either bonus scheme is not limited to the participants in the experiment. The economists who analyzed the experimental results for the State of Illinois did not recognize this possibility, nor have other conomists who have written on the issue of employer and worker subsidy programs. The final report on the Illinois experiment states that the purpose of the experiment was to determine whether payments to unemployment claimants could influence their job search behavior and whether payments to employers could influence their hiring practices even though, through bargaining, either program could influence both job search and hiring. R. Spiegelman \& S. Woodbury, Final Report, supra note 11 , at $\mathrm{x}$. The same problem appears in Lerman, supra note 63, at 175-76 ("An employer wage subsidy program aimed at target groups suffering from statistical discrimination is likely to exert a positive effect on their employment opportunities," but "[w]orker wage subsidy programs cannot exert any direct positive impact on unemployment caused by statistical discrimination."). Perhaps the failure of these researchers to take into account Coasean predictions helps to explain Coase's complaint of being ignored by his fellow economists. Schwab, supra note 4, at 1171. For an interesting speculation on why individuals might not perceive Coasean bargaining opportunities, see infra note 120 .

68. While Coaseans may be surprised that the results of the two experimental groups are so different, some other analysts will be surprised that the worker-payment rather than the employerpayment scheme generated the superior hiring performance. As David Betson has written:

Should the goal of increasing the employment of a group of disadvantaged workers through the use of wage subsidies be pursued by making payments directly to the workers or to the firms that hire them? I imagine that if this question were put to the average citizen, not to mention the average economist, an overwhelming majority would answer that payments should be made to firms, as 'bribes' to hire such workers.

Betson, Camment on Lerman, in Jobs for Disadvantaged Workers: The Economics of EMPLovinent Subsidies, supra note 63, at 180 . In fact, the Illinois Department of Employment Security may well have initially shared Betson's belief; the initial proposal called for a single program in 
nificant differences between the two groups conflict with the predictions of the Coase Theorem.

Table III shows that the average number of weeks of insured unemployment following the initial claim for compensation was reduced from 18.3 weeks for the control group to 17.7 weeks for the EPG and 17.0 weeks for the WPG. ${ }^{\text {eg }}$

TABLE III

Performance of Unemployment Insurance Claimants in Illinois Experiment

\begin{tabular}{lccc} 
& Control & EPG & WPG \\
\cline { 2 - 4 } $\begin{array}{l}\text { Proportion of } \\
\text { Claimants Who: }\end{array}$ & & & \\
Exhausted Benefits & .478 & .464 & $.446^{\mathrm{a}}$ \\
& $(.008)$ & $(.008)$ & $(.008)$ \\
Ended Benefits & .353 & $.384^{* \mathrm{a}}$ & $.408^{\mathrm{a}}$ \\
$\quad$ within eleven 11 Weeks & $(.008)$ & $(.008)$ & $(.008)$ \\
Mean Weeks of Insured & & & \\
Unemployment: & & & \\
First Spell & 18.3 & $17.7^{* \mathrm{~b}}$ & $17.0^{\mathrm{a}}$ \\
& $(.205)$ & $(.205)$ & $(.199)$ \\
Benefit Year & 20.1 & $19.7^{* *}$ & $18.9^{\mathrm{a}}$ \\
& $(.194)$ & $(.194)$ & $(.188)$ \\
Mean Benefits Paid (\$) & & & \\
First Spell & 2558 & $2446^{* \mathrm{~b}}$ & $2329^{3}$ \\
& $(33.8)$ & $(33.8)$ & $(32.9)$ \\
Benefit Year & 2786 & $2725^{*}$ & $2592^{\mathrm{a}}$ \\
& $(33.1)$ & $(33.8)$ & $(32.2)$ \\
Number & 3952 & 3963 & 4186
\end{tabular}

Source: R. Spiegelman \& S. Woodbury, supra note 11, at Tables 5-3, 5-4.

Notes: Standard errors are in parentheses.

In all cases except one, the percentages for the EPG workers differ significantly from those for WPG workers. In all but the first line, one can always reject the hypothesis that these percentages are the same at either the .01 (“**") or .05 (“*”) confidence level.

" $\mathrm{a}$ " denotes rejection of the hypothesis that the difference from the control group statistic is zero using a two-tailed test at the .01 confidence level. " $\mathrm{b}$ " denotes rejection of the same hypothesis at the .05 level.

In other words, the employer-bonus scheme reduced the average number of weeks of unemployment for all EPG workers by about two-thirds of a

which employers would receive bonuses for hiring unemployment insurance recipients. Only later was the second program involving bonuses to workers added to the experimental scheme. R. Spiegelman \& S. Woodbury, Final Report, supra note 11 , at 1.1 .

69. Table III shows the results of two statistical tests: (1) whether there is a statistically significant difference between the results in the EPG and those in the WPG, and (2) whether there is a statistically significant difference between the results in the control group and those in the respective experimental groups. For both tests all the differences in means are statistically significant at a level of at least .05 . 
week; the worker-bonus scheme reduced the average number of weeks for all WPG workers by about twice that amount. ${ }^{70}$

Simply looking at the decline in the mean weeks of insured unemployment provides little information about how the bonus schemes affected the distribution of the time intervals on unemployment about this mean. The first two rows of Table III provide some insight into this question by showing the proportion of workers in all three groups that left the unemployment rolls within eleven weeks and the proportion that remained on the unemployment rolls until their benefits were exhausted. Of the workers in the control group, $35.3 \%$ returned to work within the eleven week cutoff period, as opposed to $38.4 \%$ of the EPG workers and $40.8 \%$ of the WPG workers. Thus, both bonus schemes led to statistically significant (at the .01 confidence level) increases in the proportions of unemployment compensation recipients who returned to work quickly, although the worker-bonus scheme was significantly more effective in elevating this percentage. At the same time, both bonus schemes reduced the proportion of unemployment compensation recipients who exhausted their benefits by remaining on unemployment compensation for the full twenty-six weeks: from $47.8 \%$ for the control group to $46.4 \%$ for the EPG and $44.6 \%$ for the WPG. ${ }^{71}$ In other words, more EPG and WPG workers than controlgroup workers left the unemployment rolls within eleven weeks; but, at least for the EPG, virtually none of this improvement came from those who would otherwise have remained on the unemployment rolls until their benefits were exhausted.

These statistics provide insight into whether the bonus schemes are more effective at reducing frictional unemployment (that is, at speeding up the rehiring of individuals who would leave the unemployment rolls relatively quickly) or at assisting the hard-core unemployed, who otherwise would tend to remain unemployed at least until their unemployment compensation ran out. Some of the increase in the number of WPG workers who found jobs within the eleven-week cutoff period represented gains by members of this hard-core unemployed. This same pattern was not observed for the EPG, which showed an increase in the number of work-

70. Importantly, the figures in Table III represent the averages across all EPG and WPG workers, whether or not they participated in the program and whether or not they received a job or were paid a bonus. Confining the analysis to some subset of the entire randomly selected group would raise a potentially serious selection bias. Nonetheless, if one examines only those who "agreed to participate," the difference in performance between the two experimental groups, in terms of the proportion of workers leaving the unemployment rolls within eleven weeks and the average unemployment benefits paid over the year, is greater. R. Spiegelman \& S. Woodbury, Final Report, supra note 11, at Tablt A5-1. Moreover, as I demonstrate in Table I of this article, restricting the analysis to only those who agreed to participate does not eliminate the differential performance of the two groups in terms of obtaining bonuses.

71. The decrease in the proportion of claimants who exhausted their benefits, compared to that of the control group, was not significant for the EPG but was significant for the WPG (at the .01 level). The difference between the EPG and WPG in this proportion was not statistically significant. 
ers leaving unemployment quickly but showed no significant decrease in those who exhausted their benefits.

These bonus programs reward those who return to work within eleven weeks of filing for unemployment compensation, provided the workers remain on the job for at least four months. But what if everyone who filed for unemployment compensation was simply looking for a paid vacation of twenty-six weeks? Conceivably, this bonus program might induce workers to return to work within the eleven-week period only to have them quit or be terminated after the bonus was collected. They could then be right back on the unemployment compensation rolls. The program would have served only to break up their spell of unemployment and not to diminish the ultimate amount of time they spent collecting unemployment insurance, which is Illinois' primary concern. Therefore, it is useful to look not only at the experience of covered workers in their initial spell of unemployment (which would be used in determining whether they would qualify for a $\$ 500$ bonus) but also at the amount of time these workers spent on the unemployment rolls for the entire year after filing their initial unemployment claim (the "benefit year"). An examination of the average number of weeks that workers collected unemployment compensation for the benefit year shows that there may have been a tendency for bonus recipients to return to collecting unemployment insurance after leaving to accept a job within the eleven-week cutoff period, particularly for the EPG workers. ${ }^{72}$

\section{The Estimated Savings in Unemployment Compensation Payments}

To illustrate the effect on the Illinois treasury of the decrease in the number of insured weeks of unemployment, Table III presents the total amount of unemployment compensation paid for the three groups in the first spell of unemployment and the entire benefit year. In general, the program did reduce unemployment insurance payments-more for the first spell than for the entire year and more for the WPG than for the EPG. While the average payment made to the control group in the benefit year was $\$ 2786$, the EPG workers received on average $\$ 61$ less than this (insignificantly different at the .05 level) and the WPG workers received $\$ 194$ less (significant at the .01 level). Although these numbers may seem small, they imply that the bonus experiment reduced both the state and Federal governments' unemployment compensation expenditures for the

72. In other words, while there is a statistically significant difference between the length of the control group's first spell of insured unemployment and the length of the EPG's first spell of insured unemployment, this difference becomes insignificant when one looks at the entire benefit year. On the other hand, the difference between the control group's and the WPG's total time spent on unemployment remained statistically significant for the entire benefit year. This might suggest that some employers were induced by the employer-payment bonus to hire workers who might not otherwise have been hired. After some time on the new job, these workers may have ended up back on unemployment compensation after quitting or being fired. 
WPG by $\$ 812,084$ ( $\$ 194$ per worker times 4186 workers) while costing only $\$ 285,000$ in bonus payments ( $\$ 500$ times the 570 workers who received bonuses). The net benefit of the worker-bonus experiment therefore was $\$ 527,084$. Similarly, the unemployment compensation savings for the EPG were $\$ 241,743$ ( $\$ 61$ per worker times 3963 workers) and the bonus costs amounted to $\$ 56,000$ ( $\$ 500$ times 112), resulting in a net benefit for the employer-bonus experiment of $\$ 185,743$. In total, the bonus experiment yielded net savings of $\$ 712,827$.

One important qualification must be raised. The estimate of the savings in unemployment insurance payments was obtained by computing the total payments for the control group and seeing how much smaller the payments were for the EPG and WPG. The implicit assumption is that the control group results were not affected by the experiment. But if employers responded to the program by simply hiring bonus workers in preference to non-bonus workers, there would be no direct job creation effect and only a "reshuffling of the unemployment queue." ${ }^{\text {"73 }}$ While this factor suggests caution in using these results to advocate widespread implementation of such a scheme and may invalidate the conclusion that substantial savings were realized, it does not affect the primary concern of this paper, which is to evaluate the operation of the Coase Theorem. For whatever reasons, the results under the two bonus schemes remain quite different.

\section{The Results By Race and Sex}

One of the primary questions to emerge from the findings presented thus far is whether the different responses to the two different bonus schemes were caused by factors such as transaction costs and possible asymmetries inherent in the experiment or by individual factors such as intelligence, education, socialization, and willingness to negotiate. Since the latter factors are not uniform across demographic groups, disaggregating the data according to race and sex, as illustrated in Table IV, yields additional insights concerning the effects of the two bonus schemes.

73. Hui \& Truedi, Duration Dependence, Targeted Employment Subsidies and Unemployment Benefits, 31 J. Pub. ECoN. 105, 115 (1986) (analyzing Australian Special Youth Employment and Training Program). This gloomy prospect is real, but not inevitable. First, if employers consider the bonus as an employment subsidy they may hire more workers-that is, they will move down their demand curve for labor. Second, if the program induces greater search by workers and shorter spells of unemployment, then unemployment taxes (and therefore the total cost of labor) will fall and a new higher-employment equilibrium would ultimately be reached. Most studies have concluded, however, that the demand for low-wage labor is inelastic, which suggests that the expansion of jobs will be modest. See Clark \& Freeman, How Elastic is the Demand for Labor?, 1980 Rev. Econ. \& STATisTICs 509,518 (estimating the elasticity of demand for labor at .4 or .5); Brown, Gilroy, \& Kohen, The Effect of the Minimum Wage on Employment and Unemployment, $20 \mathrm{~J}$. ECON. LiteratURE 487 (1982). 
TABLE IV

Participation in and Use of the Two Bonus Schemes by Race/Sex Percentage That:

\begin{tabular}{|c|c|c|c|c|c|}
\hline & $\begin{array}{c}\begin{array}{c}\text { Agreed } \\
\text { to } \\
\text { Participate }\end{array} \\
\frac{(1)}{}\end{array}$ & $\begin{array}{c}\text { Submitted } \\
\frac{\mathrm{NOH}^{\mathbf{1}}}{(2)}\end{array}$ & $\begin{array}{l}\text { Received } \\
\frac{\text { Bonus }}{(3)}\end{array}$ & $\begin{array}{c}\text { Qualified } \\
\text { For Bonus } \\
(4)\end{array}$ & $\begin{array}{r}\text { Receive } \\
\text { Bonus } \\
\text { of Thos } \\
\text { Qualified } \\
(5)\end{array}$ \\
\hline \multicolumn{6}{|l|}{ EPG } \\
\hline $\begin{array}{c}\text { White/Female } \\
(1166)\end{array}$ & $61.9^{* *}$ & $7.0^{* *}$ & $4.6^{* *}$ & $28.0^{\mathrm{a}}$ & $16.5^{* *}$ \\
\hline $\begin{array}{c}\text { White/Male } \\
\text { (1399) }\end{array}$ & $61.9^{* *}$ & $6.4^{* *}$ & $3.6^{* *}$ & 25.8 & $13.9^{* *}$ \\
\hline $\begin{array}{l}\text { Black/Female } \\
\quad(504)\end{array}$ & $65.1^{* *}$ & $1.2^{* *}$ & $0.4^{* *}$ & 15.3 & $2.6^{* *}$ \\
\hline $\begin{array}{c}\text { Black/Male } \\
(510)\end{array}$ & $70.4^{* *}$ & $1.8^{* *}$ & $0.4^{* *}$ & $12.0^{*}$ & $3.3^{* *}$ \\
\hline \multicolumn{6}{|l|}{ WPG } \\
\hline $\begin{array}{l}\text { White/Female } \\
(1170)\end{array}$ & 85.1 & 21.0 & 17.6 & $30.0^{a}$ & 58.7 \\
\hline $\begin{array}{l}\text { White/Male } \\
\text { (1553) }\end{array}$ & 88.0 & 22.2 & 17.0 & $27.7^{a}$ & 61.4 \\
\hline $\begin{array}{l}\text { Black/Female } \\
\quad(512)\end{array}$ & 80.0 & 10.4 & 6.3 & 17.8 & 39.5 \\
\hline $\begin{array}{c}\text { Black/Male } \\
(538)\end{array}$ & 81.4 & 9.3 & 6.3 & 16.5 & 38.2 \\
\hline
\end{tabular}

Source: R. Spiegelman \& S. Woodbury, supra note 11, at Table 7-2; Woodbury \& Spiegelman, Randomized Trials in Illinois, supra note 11, at Table 7; and public use tapes.

Notes: ${ }^{1}$ Actually submitted an NOH form, whether or not the Illinois adminstrative records clearly indicate that they obtained work within eleven weeks.

2In this table, "qualified" refers only to the employment eligibility requirement: obtaining work within eleven weeks and remaining at work for four months, whether or not the worker participated in the experiment.

${ }^{3}$ The parenthetical figures give the size of each group, to which all the percentenges, except those in the last column, should be applied. Column (5) equals column (3) as a percentage of column (4).

Except for the three cases indicated in column (4), the percentages for EPG workers differ significantly from those for WPG workers. In all but those cases, one can always reject the hypothosis that these percentages are the same at either the .01 ("**") or .05 ("*") confidence level.

" $a$ " denotes rejection of the hypothesis that the difference from the control group statistic is zero using a two-tailed test at the .05 confidence level. Only the EPG and WPG percentages in column (4) could be compared.

Interestingly, as a result of the bonus schemes white women experienced the greatest improvement in labor market outcomes, as measured by the percentage qualifying for bonuses by obtaining employment within eleven weeks and retaining it for at least four months (column (5)). ${ }^{\mathbf{7 4}}$ In-

74. White women also showed the greatest reduction in unemployment compensation benefits received. R. Spiegelman \& S. Woodbury, Final Report, supra note 11, at Table 6-8. 
deed, white women were the only group that responded significantly to both the employer-bonus and worker-bonus schemes, although the latter was clearly stronger. White males showed no response to the employerbonus scheme and a significant response, although smaller in magnitude than that of white women, to the worker-bonus scheme. Black men and black women workers showed no statistically significant response to either scheme. $^{75}$

\section{Differing Rates of Receiving Bonuses and Improved Labor Market Performance}

The percentage of EPG employers receiving bonuses is smaller for every race/sex category than the percentage of WPG workers receiving such bonuses (column (3)). These differences by category are determined by two factors: the ultimate number who qualify by obtaining jobs within eleven weeks and remaining at work for four months (column (4)); and the proportion of the above group that actually receive bonuses (column (5)), which is a function of the group's level of participation. Table IV shows that blacks have much lower proportions than whites for both these elements, but clearly the difference between the black and white EPG workers is the most dramatic. Thus, most of the variation between the two bonus groups in the difference between the number of bonuses paid to white as opposed to black workers (or their employers) comes from the much lower likelihood that EPG blacks meeting the employment eligibility requirements (or their employers) will take the steps needed to secure bonuses that will be paid to EPG employers.

Surprisingly, though, the differences in bonus receipt among the four race/sex categories do not strongly correlate with the numbers who initially signed the agreement to participate. In fact, for the EPG, white women had the lowest participation rate $(62 \%)$ of any of the race-sex categories, yet they were the only group to experience significantly better performance than their control-group counterparts. ${ }^{76}$ Black men in the

75. While the proportions of black males in the two experimental groups who met the qualifications for receiving a bonus were not significantly different from the corresponding control group proportion, the EPG and WPG proportions were different at the .05 level. The reason for this somewhat anomalous result is that black males in the EPG actually qualified at a somewhat lower rate than their contral group counterparts ( $12.0 \%$ versus $12.7 \%$ ).

76. Even though white men participated in the EPG more frequently than white women $67 \%$ verus $62 \%$ ) white men in this employer-payment group showed no improvement in labor market performance vis-a-vis the control group, while white women showed a sizable improvement. In analyzing these results it is important to recognize that a group can have a high rate of receiving bonuses but how no improvement in obtaining jobs when compared with the control group. This is exactly what happened to white males in the EPG: They submitted notices of hire and qualified for bonuses at almost the same rate as EPG white women, but unlike the white women, the white men did not return to work faster than their control group counterparts. In other words, it appears that virtually all of the white men hired in the EPG would have been hired in the absence of the program. This suggests that employers' eagerness to hire white males was not significantly enhanced by the prospect of a $\$ 500$ bonus. 
EPG had the highest participation rate of the four race-sex categories (70\%), yet the program had virtually no impact on their return to work, and less than one-half of one percent actually generated bonuses for their employers. In the WPG, white males had the highest percentage of participation (88\%), while black females had the lowest $(80 \%)$.

That the percentage of workers in a particular race/sex category qualifying for (as opposed to receiving) bonuses is not statistically different between the EPG and WPG does not imply that the Coasean invariance prediction is confirmed. As I argued above, absent transaction costs, whenever it is efficient to receive a bonus under one scheme, it will be efficient to receive a bonus under the other. But if one looks, for example, at the performance of black females, the percentage receiving bonuses and the number of bonuses paid as a proportion of those who qualified for bonuses were more than an order of magnitude greater for the WPG than for the EPG. Clearly, then, even though the ultimate labor market performance of black females was not significantly changed by the different bonus schemes, the extent of bonus payments under the two programs was vastly different. ${ }^{77}$

\section{Differing Wage and Tenure Rates}

Table IV presents us with a puzzle. While the worker-payment scheme generally benefited white workers, the employer-payment scheme benefited only white females and not white males. Can the large differences in earnings between white males and white females explain these differences in responsiveness to the employer-payment scheme? Under some circumstances this factor would not be important. For example, if two workers show up for a job who are identical in every respect except that one is in the EPG, then a profit-maximizing employer should select the EPG worker regardless of the salary attached to the job. Nonetheless, one's intuition is that a $\$ 500$ bonus will be a greater aid to securing a job paying $\$ 3.35$ per hour than one paying $\$ 300,000$ per year. The $\$ 500$ bonus would constitute a higher proportion of the earnings of a minimum-wage worker than that of a top corporate executive.

To formalize this intuition, consider the case of an employer who tries to estimate the productivity of a job applicant. Since the employer does not have perfect knowledge of the candidate's abilities, the employer's estimates of the worker's productivity will fall into some distribution around the true value. Figure III represents just such a distribution of estimates for two workers: worker $\mathrm{A}$, with a true value of $\$ 5$ per hour, and worker $B$, with a true value of $\$ 10$ per hour. ${ }^{73}$

77. In general, blacks made virtually no use of the EPG program. Black male EPG workers obtained only two bonuses, as did black female EPG workers.

78. The figure assumes that the estimates are unbiased and normally distributed and that the 


\section{Figure III}

The Distribution of Expected Productivity Estimates for Two Workers with Different Abilities

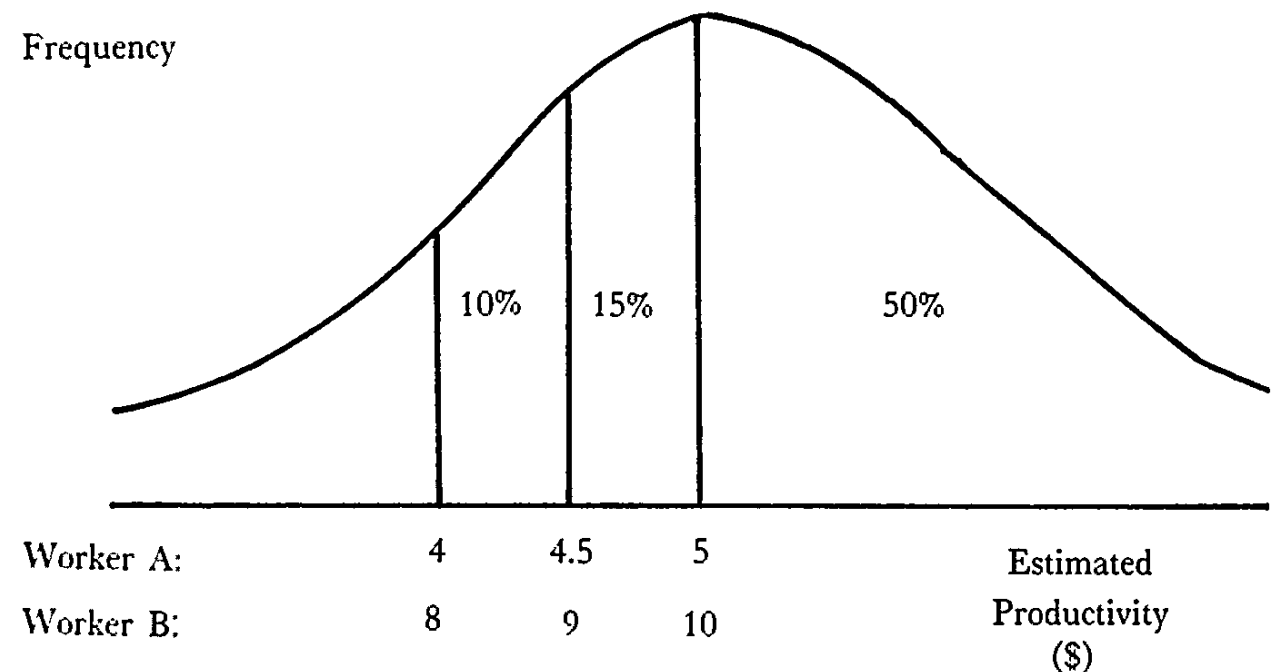

If $A$ and $B$ were to apply for jobs paying $\$ 5$ and $\$ 10$ respectively, both would be hired if the employers had perfect information. Instead, there is only a $50 \%$ chance that each of these workers will be hired because the estimates of worker productivity are probabilistic rather than certain. If the jobs under consideration are to last for four months, the $\$ 500$ bonus could be thought of as a subsidy of roughly $\$ 1$ per hour. Consequently, the introduction of the bonus induces the EPG employer to hire $\mathrm{A}$ as long as the estimated productivity is at least $\$ 4$ and $\mathrm{B}$ as long as the estimated productivity is at least $\$ 9$. But note the effect of the bonus scheme: The chance that A will be hired has increased from $50 \%$ to $75 \%$, while B's chance has only improved from $50 \%$ to $65 \%$. Therefore, it would seem that the $\$ 500$ bonus would tend to improve the hiring rate of lower paid workers more than higher paid workers.

Since white males earn considerably more than white females, it may not be surprising to find that the $\$ 500$ bonus had a more pronounced effect on white female workers. But if lower pay were the only explanation for the greater impact of the bonus on EPG white females, one would expect that EPG black females would also have profited from the bonus scheme, although they did not. Perhaps two factors are at work in determining how large the bonus looms in the minds of employers: the wage of

likelihood of deviating from the true productivity by a certain percentage is the same for both jobs. 
the particular job being filled and the predicted tenure of the sex-race category for the particular EPG worker. Predicted tenure is important to an EPG employer because he cannot obtain the bonus if the worker quits before four months. Accordingly, one would expect the greatest impact from the EPG for lower-paid workers with high expected tenure. This would suggest a greater impact for white females than for other groups because their expected tenure is high (as high as for white males) but their wages are low (as low as for black females). ${ }^{79}$

\section{E. Did the Parties Bargain Over the Wage?}

If the parties fail to bargain over the distribution of the bonus or over the wage, the mechanism that generates the identity prediction is severed. Without bargaining, the employer-payment scheme can only influence the behavior of employers and the worker-payment scheme can only influence the behavior of workers. Unfortunately, the designers of the Illinois experiment did not conceive of the possibility of bargaining and therefore did not ask questions about possible bargaining in the follow-up survey. ${ }^{80}$ Nonetheless, we can seek insight into whether bargaining over the wage occurred if we examine the effects of the bonus schemes on the earnings of those workers from each group who found jobs.

It turns out, however, that it is difficult to predict the effect of the bonus schemes on the earnings of workers from each group. To reduce the complexity of this problem, I will assume that the entire $\$ 500$ bonus will either be retained by the party to whom it was originally assigned or transferred to the opposing contractual party. ${ }^{81}$ Table $V$ can then be used to ascertain the expected effect of each bonus scheme on the wages of EPG and WPG workers (vis-a-vis the wages of control group workers).

79. In recent years young female workers have closed the formerly large tenure gap with young male workers, but black workers of both sexes continue to have significantly lower expected tenure. At the same time, white men continue to earn the most, white and black women the least, and black men in between. See J. Donohue, The Changing Relative Job Exit Rates of Young Male and Female Workers (Sept. 1987) (unpublished manuscript on file with author). The argument in the text assumes that the tenure and wage patterns observed in the labor market as a whole also apply to the sample of workers receiving unemployment insurance. Indeed, the quarterly earnings of control-group workers from the Illinois experiment adhered to the same pattern: white males earned 83798 , black: males $\$ 3091$, white females $\$ 2623$, and black females $\$ 2474$. While we do not have precise information on the job tenures of workers participating in the Illinois experiment, a crude measure of the job exit rate for control group workers is available: the percentage of workers who obtained a job within eleven weeks who did not remain for four months. This measure supports the view that whites have substantially longer expected tenure than black males: white males, $25.7 \%$; black males, $35.7 \%$; white females, 24.4\%; and black females, $26.8 \%$. The difference between the job exit rate for white and black females is roughly $10 \%$.

80. See supra note 67.

81. Hence, I will not consider the case in which the parties divide the bonus. 
TABLE V

Effect of Bonus on Wages of Experimental Groups as Compared to Control Group

Bonus Transferred to or Retained By: WPG EPG

\begin{tabular}{cll}
\hline The Worker & Lower Wages* & Lower Wages \\
The Employer & Higher Wages & Higher Wages \\
\hline
\end{tabular}

* indicates likely impact if tax (or any other) considerations prompt WPG workers to retain the bonuses.

Consider first the situation of two workers who are identical except that one is in the control group and one is in the WPG. Assume that without any bonus both workers would keep searching for work until they found a job that paid, say, $\$ 3000$ in the first quarter after leaving the unemployment rolls. The WPG worker might accept an offer that paid only, say, $\$ 2800$ because the $\$ 500$ bonus would elevate her earnings above the desired threshold. In this event the control-group worker would be likely to remain on the unemployment rolls longer but would ultimately show first quarter earnings of $\$ 3000$, while the WPG worker would leave the unemployment rolls more quickly (certainly within eleven weeks) and show first quarter earnings of only $\$ 2800$. Similarly, if the WPG worker is one of a number of applicants for a job paying $\$ 3000$, she might suggest the $\$ 2800$ figure as a way to increase the likelihood of being offered employment. Consequently, the effect of the bonus would be to lower measured earnings for the WPG worker who retained the WPG bonus, even though total income of earnings plus bonus would be higher for the WPG than for the control group.

Note that the WPG worker might also offer to transfer the $\$ 500$ bonus to the potential employer. Such an offer could presumably increase the speed at which the worker secured employment that paid $\$ 3000$. Yet the WPG worker might realize that a job paying more than $\$ 3000$ might still be within reach. By using the $\$ 500$ bonus to get a better job, the WPG worker would be likely to show higher earnings than the control group counterpart.

One can demonstrate the analogous result for the EPG. If, in the absence of a bonus, the workers would wait for a $\$ 3000$ wage, then equipping these workers with a $\$ 500$ bonus to be paid directly to the employer will likely elevate the employers' demand for labor. On the other hand, if the $\$ 500$ would be transferred to the EPG workers, the workers will be willing to take a lower paying job than their control group counterparts.

The lesson of Table V can be summarized as follows: If the bonus is retained by the worker (whether the worker is in the EPG or the WPG), 
one would expect to see lower wages vis-a-vis the control group; if the bonus is retained by the employer (whether from hiring a WPG or an EPG worker), one would expect to see higher wages vis-a-vis the control group. Put simply, if one receives more in the way of bonus benefits, one will make greater wage concessions. Were it certain that the designated recipients of the bonuses-the EPG employers and the WPG workers-either always retained or always transferred their bonuses, then Table $\mathrm{V}$ would yield predictions about the effect of the bonuses on the wages of EPG and WPG workers. If the bonuses are sometimes retained and sometimes transferred, however, the effects on wages will tend to be offset.

Is there any reason for parties to prefer bargaining over the wage to bargaining over the bonus? On the one hand, bargaining over the bonus might make more sense, as it is a more precise instrument than a wage agreement, which would probably extend beyond four months. For example, if an EPG worker demands a higher wage because the employer will be receiving a $\$ 500$ bonus, there is the problem of what to do once the employer has received the bonus; the worker is now securing a higher salary that presumably must at some point be adjusted downward. If the EPG worker asks for a portion of the bonus instead of a higher wage, the bargain is completed in one step and the wage rate can be settled right from the start. On the other hand, some employers might feel more comfortable bargaining over wages than over cash inducements. Perhaps more important, as I show in Part IV(B)(2)(a) below, tax considerations may lead WPG workers to retain the bonuses and offer offsetting wage adjustments to the opposite party when necessary to achieve the efficient outcome. This device may be needed to avoid double taxation of bonus dollars.

Without any data on whether or not nominal beneficiaries retained the full bonus, we simply cannot predict the effect on wages of qualifying for a bonus. While the tax consideration might seem compelling, the parties might simply treat bargained transfers of bonus dollars as "off the books," thereby diminishing the importance of this factor. Even without strong a priori predictions, though, it is still useful to explore two types of evidence on the effect of the bonus programs on earnings: the mean earnings of the entire EPG and WPG (with breakdowns by race and sex) and regression estimates of the earnings of EPG and WPG workers that reveal the effect of program participation.

\section{Mean Earnings of EPG and WPG Workers}

The mean earnings in the three months following the termination of unemployment benefits were virtually identical for the control group and the WPG ( $\$ 3121$ and $\$ 3130$ ). The mean earnings of the EPG ( $\$ 3066)$ were slightly, though insignificantly, lower than those of the other groups. 
Two factors are responsible for the lower average wage of the EPG. First, although wages paid to females in the two groups were virtually identical (\$2571 in the control group and \$2575 in the EPG) the earnings of EPG male workers $(\$ 3500)$ were lower than those of control-group male workers (\$3565). Second, since the employer bonus was more successful in stimulating employment for female workers than for male workers, the heavier weighting of the lower female earnings further reduced the aggregate mean earnings for the EPG ${ }^{\mathbf{2}}$

To summarize these results, it appears that there was virtually no difference between the wages earned by WPG workers and those earned by control-group workers and no difference between the wages earned by female EPG workers and those earned by their control-group counterparts. These findings suggest that either no bargaining over the wage or bonus took place for these workers, or the effects of bargaining over the wage and the bonus exactly offset each other. One might think that the lower earnings of EPG males vis-a-vis the control group implies that male EPG workers succeeded in extracting some of the bonus from their employers through bargaining. But this explanation seems unlikely because even if we assume that each of the 100 male EPG workers who filed an $\mathrm{NOH}$ form succeeded in negotiating a $\$ 500$ bonus from his employer and therefore took an offsetting wage reduction, we cannot explain a drop in mean wages of $\$ 65$ for all 1909 EPG workers. ${ }^{83}$

\section{Regression Estimates of Earnings}

All the average-earnings figures presented above represent the earnings of the entire population of any particular category, such as white male WPG workers, regardless of whether and to what extent they participated in the program. Since the predicted effects of altered wages for WPG and EPG workers would apply only to workers who could expect to earn a bonus, perhaps we can observe such effects if we focus more sharply on those who effectively used the bonus programs. To assess the effect of program participation on earnings, I estimated the following earnings

82. One can eliminate the second selection effect by computing the mean earnings for the EPG and WPG using the percentages of male and female workers in the control group as the weights. When this is done, the average earnings of the WPG and EPG ( $\$ 3122$ and $\$ 3087$, respectively) are quite close to the control group earnings of $\$ 3121$.

83. One-hundred male EPG workers filed NOH forms, although only 52 of them ultimately earned bonuses. R. Spiegelman \& S. Woodbury, Final Report, supra note 11, at Table 7-2. Nonetheless, if all 100 negotiated to obtain some of the bonus for themselves but were forced to take somewhat of a pay reduction in return, then the maximum amount of reduction they would each be willing to take is $\$ 500$ (or less if they did not negotiate to acquire the entire bonus). But such a pay reduction for the 100 male EPG workers would only reduce the mean wages of all 1909 male EPG workers by $\$ 26$, which is substantially less than the observed decrease in wages of $\$ 65(\$ 26=100 / 1909 \times \$ 500)$. Therefore, bargaining by itself obviously did not lead to the decrease in wages of male EPG workers, and some other factor (such as possible stigmatization) may be responsible. See infra Section IV $(B)(3)$. 
function to predict the earnings of EPG and WPG male and female workers: $^{84}$

Earnings $^{85}=\mathrm{f}$ (age, race, Hispanic, highest previous earnings, ${ }^{86}$ weekly unemployment compensation benefit, ${ }^{87}$ dependent's allowance, ${ }^{88}$ agreed to participate, submitted $\mathrm{NOH},{ }^{89}$ and hired within eleven weeks).

The results from the four regression equations are presented in the Appendix ${ }^{\mathbf{8 0}}$ but the most important results for present purpose are presented in Table VI.

TABLE VI

Effect on Earnings of Re-employed Workers

WPG Males

WPG Females

EPG Males

EPG Females

Agreed to Participate
$-\$ 300$
-145

$-423$

$-450$
Submitted $\mathrm{NOH}^{2}$

$\$ 1137$

1041

499

594

Notes: "The figures depicted in this column are the coefficients on the "Agreed to Participate" dummy as shown in the Appendix.

"The figures presented in this column are the coefficients on the "Submitted NOH" dummy.

The second column, controlling for the above observable factors, shows that those who submitted NOH forms earned roughly $\$ 500-\$ 600$ more in the EPG and roughly $\$ 1000-\$ 1100$ more in the WPG than those who did not. Clearly, the boost in earnings associated with filing an $\mathrm{NOH}$ was substantially greater for WPG workers than for EPG workers. It is intriguing to note that EPG males earn almost exactly $\$ 500$ more if they file an NOH. This may suggest that since the employer gets to keep the anticipated $\$ 500$ bonus, the worker receives in return an additional $\$ 500$

84. Regression analysis is a statistical tool used to estimate the relationship between a dependent variable (in this case, earnings) and a set of explanatory variables (such as age, race, etc.). When appropriate conditions apply, the regression procedure identifies both the magnitude of the effect of any variable (e.g., holding other attributes constant whites earn $\$ 500$ more per quarter than blacks) and the degree of confidence (i.e., statistical significance) associated with this measure.

85. Earnings are measured by the amount earned in the first full quarter after the worker left the unemployment compensation rolls.

86. I derived this variable, which is intended to provide information about the worker's productive potential, by taking the highest quarter of earnings from each individual's "base period." The base period in Illinois is the first four of the last five completed quarters preceding the filing for unemployment benefits. R. Spiegelman \& S. Woodbury, Final Report, supra note 11, at 4.6.

87. The size of the unemployment benefit gives some indication of the steadiness of work during the base period and therefore will be somewhat predictive of the steadiness of work (and thus of the amount of quarterly earnings) following the spell of unemployment compensation.

88. The dependent's allowance primarily reveals whether the worker is supporting a family, a factor which can influence work effort and hence earnings.

89. In this equation, this variable equalled one if an NOH was submitted or a bonus was paid.

90. Among the most consistently significant variables were "Submitted NOH" and "Highest Previous Earnings," both of which affected earnings positively, especially in the worker-payment scheme 
in compensation. But I doubt this explanation is correct for a number of reasons.

First, the discussion above of the mean earnings of EPG males suggested that the EPG males earned less than their control group counterparts. Second, Table VI also suggests that the benefit associated with filing an NOH was even greater for both male and female WPG workers and female EPG workers, and there was no overall increase in mean earnings for these groups. I conclude therefore that the regression figures are capturing some unobserved productivity features: Other things being equal, a worker who is adroit enough to file an NOH is likely to be more talented generally than a worker who fails to file an $\mathrm{NOH}^{91}$ The selection effect probably explains at least some of the apparently higher earnings across the four groups associated with filing $\mathrm{NOH}$ forms, but it does not explain why filing an NOH is so important for WPG workers. If this substantial increase in the earnings of WPG workers is truly a function of workers' negotiating in anticipation of receiving a bonus, it would seem to suggest that WPG workers promise their bonuses to employers and collect higher earnings in return. But the fact that mean earnings of WPG workers were virtually identical to control group workers raises doubts about this conclusion. ${ }^{22}$

In any event, the data seem to refute the proposition that the named beneficiaries of the bonuses kept their bonuses and bargained in an offsetting fashion over the wage. While there is admittedly considerable uncertainty about the issue because of gaps in the data, the information on earnings is perhaps most consistent with the view that the bonus schemes allowed white WPG workers and white female EPG workers to secure work more quickly. The bonus scheme, however, did not enable these workers to obtain different jobs than they would have obtained without the bonus programs. ${ }^{93}$ It is difficult to tell a story that squares this outcome with the distribution prediction, ${ }^{\mathbf{9 4}}$ since the far greater number of bonuses paid to (and apparently retained by) WPG workers suggests that

91. The eudence from the regression analysis is probably indicative of interesting selection effects, but to properly identify the coefficients of interest requires more sophisticated econometric techniques. Hausman \& Taylor, Panel Data and Unobservable Individual Effects, 49 Econometrica 1377 (1981); Heckman, Sample Selection Bias as a Specification Error, in Female Labor SuPPly: TheORY AND Estimation (J. Smith ed. 1980).

92. If the 666 WPG workers that filed $\mathrm{NOH}$ forms had really earned, say, $\$ 500$ more than other workers, then it would have raised the mean wage of the 4186 workers by roughly $\$ 80(\$ 79.55=$ $666 / 4186 \times \$ 500)$. This appears not to have happened.

93. We know from Table IV that these two groups of workers experienced a significant increase vis-a-vis their control-group counterparts in the rate of qualifying for bonuses. At the same time, their wages are virtually identical to those of the control group, indicating that the bonus program did not alfect the type of job they ultimately secured.

94. The distribution prediction is that EPG and WPG workers will earn the same total amount, in luding salary and bonus. But if EPG and WPG workers earn the same salaries and WPG workers earn more bonuses, then clearly WPG workers earn more in total than EPG workers. 
WPG workers earned higher total income under the bonus program than EPG workers did.

\section{Factors That Might Undermine Coasean Predictions}

While the results of the experiment contradict the Coasean predictions of efficiency of outcomes, invariance of hiring practices and of bonus payments, and equal distribution of income, the question arises whether and to what extent transaction costs or asymmetries between the bonus programs-as opposed to breakdowns in the Coasean framework-are responsible. It is obviously not helpful to define "transaction costs" to include anything that prevents Coasean predictions from occurring; this would turn the Coase Theorem into an empty tautology. I therefore define transaction costs to include anything that makes it costly to negotiate or enforce a bargain over the distribution of the bonus. To the extent transaction costs in, or asymmetries between, the two bonus programs explain the results of the Illinois experiment, we cannot conclude that the Coase Theorem has been contradicted. If, however, other factors-such as ignorance or irrationality on the part of participants-explain the results, then I would argue that the Coase Theorem has, in a meaningful sense, failed this real-world test.

Sections A through $\mathrm{C}$ discuss each of the following possible explanations for the divergent results of the two bonus programs: transaction costs, asymmetries in the programs, and factors suggesting the Coase Theorem has failed the real-world test. In considering why the performances of the EPG and WPG workers were so different, recall that the payment schemes were valuable to workers because the bonus could be used both to help the workers directly or indirectly obtain more money and to help the workers obtain jobs. In evaluating the three potential explanations for the results of the Illinois experiment, it will be useful to distinguish between those factors that limit bargaining, and thus impair the "value in exchange" of bonuses under one or both bonus schemes, and those factors that impair the "value in use" of employer bonuses. ${ }^{95}$ Section $\mathrm{D}$ then analyzes the effect of imperfections in the labor market caused by minimum wage laws and concludes that these imperfections cannot explain the findings of this experiment.

95. Airlines restrict the "value in exchange" of frequent flyer coupons by forbidding the recipient to transfer them to another person, but these coupons obviously have significant "value in use" because they enable the recipient to obtain free air travel and other valuable services. Similarly, if for some reason a WPG worker was forbidden or prevented from using the worker-payment bonus to bargain for a job, it would have no "value in exchange" but would still have "value in use"; as long as the worker meets the employment criteria of the experiment, the bonus will provide him with $\$ 500$ that can be used to obtain valuable goods and services. As we will see, it is possible that the "value in use" of the employer bonus-but not the worker bonus-was impaired. 


\section{A. Transaction Costs}

The analysis of the bargaining model discussed in Part II(C) emphasized that costless bargaining is the conduit that allows resources to flow to their highest valued use. This idea gives rise to the metaphor of the Coasean River in the title of this Article. As transaction costs increase, the conduit becomes restricted and the free flow of resources becomes impaired. If transaction costs become prohibitive, no bargaining will occur; the conduit is severed and resources remain with their original possessor. In such a case efficient outcomes cannot be assured, and identical outcomes, even in a contract setting, will occur only by chance.

As noted in Part II(A), three factors indicate that bargaining costs in this experiment were relatively low: (1) the employment contract involved only two parties, who were not locked in a bilateral monopoly; (2) even without the bonus, the parties would have needed to reach an agreement on an employment contract, and the additional bargaining needed to reach an agreement on the distribution of the bonus was relatively modest; and (3) the thickening labor market caused transaction costs to be at their lowest level across the business cycle. ${ }^{96}$

But transaction costs may have been higher than at first appeared. First, institutional constraints imposed by personnel offices and fixed wage offers, whose very purpose might be to eliminate bargaining by lowlevel employees of the firm, would have impeded the ability of workers to strike individualized wage bargains with the aid of a $\$ 500$ bonus. $^{97}$

Second, even though bargaining costs were relatively low-indeed it is difficult to think of another real-world example in which bargaining costs would be as low as in this case $\mathrm{e}^{\mathbf{8}}$ - enforcement costs may have been significant. The costs of explaining the bonus scheme and agreeing on a division of the $\$ 500$ would seem to have been relatively modest if the parties recognized the opportunity to bargain and were willing to rely on an oral agreement. But oral agreements are susceptible to abuse. A WPG worker who succeeded in obtaining employment by promising to give all or part of a bonus to the employer could always collect his bonus from the state of Illinois and then quit his job, forcing the employer to sue to obtain the promised money. If the problems of enforcement loomed large in the minds of the participants, they might simply have refused to bargain over the bonuses; this possibility impairs the value in exchange of both bonuses

\footnotetext{
96. See supra text accompanying notes 14-25.

97. For example, even without the existence of the bonus, job applicants could always offer to work for less than the posted wage. This behavior is unusual in the non-union sector and impossible in the nearly $20 \%$ of the workforce that is unionized. Solow, On Theories of Unemployment, 70 AM. ECoN. REv. 1, 5 (1980). The Illinois study, by restricting the experiment to workers who registered at Job Service offices, tried to eliminate union workers who find jobs through hiring halls. See R. Spiegelman \& S. Woodbury, Final Report, supra note 11, at 2.1.
}

98. See discussion infra Section IV(B). 
but not their value in use. On the other hand, even if this fear had been great, the problem would have been mitigated at least to some degree, since the nominal beneficiary could simply have retained the bonus and bargained instead over the wage.

But the problem of enforcement could conceivably have infected not only the value in exchange of both schemes but also the value in use of the employer-bonus scheme, if the actors behaved opportunistically. If both parties knew of the presence of the bonus scheme, then any agreement over the division of the bonus may have induced opportunistic threats to terminate the employment relationship just prior to the four month cutoff in an effort to disgorge all or part of the bonus from the other party. For example, an EPG worker who tells her employer that the employer will receive $\$ 500$ if the worker is hired can simply threaten to leave just before the bonus is earned, thereby depriving the employer of the bonus entirely. Moreover, the employer could make a similar threat to undermine any agreement that gave all or part of the bonus to the worker. ${ }^{98}$

This problem arises because a bilateral monopoly, although absent initially, may have been created by the establishment of the employment relationship. Without enforceable contracts either party could try to capture the bonus by threatening to terminate the employment relationship just before the right to a bonus vested. The parties could have resolved the problem, however, by drafting contracts and seeking to enforce them when necessary, although the costs of doing so obviously would have diminished the attractiveness of both bonus schemes.

Note that these game-theoretic elements, by explaining the impairment not only of the value in exchange of both schemes but also of the value in use of the EPG, can provide a better explanation than the transaction cost story of the finding that the worker-payment scheme generally performed better than the employer-payment scheme. A WPG worker could avoid the threat of opportunistic behavior simply by declining to inform the employer of the bonus-an option not available to an EPG worker. Thus, if the threat of being deprived of an earned bonus were a serious concern, WPG workers would never have wanted to tell employers of the existence of the potential $\$ 500$ award. Even if reputational considerations kept all employers from engaging in this behavior themselves, they might not trust workers and therefore might not be willing to bargain with either EPG or WPG workers over the assignment of the bonus. ${ }^{100}$ If all employers expected opportunistic behavior by employees, the employer bonus would

99. One might expect that employers have more to lose by engaging in this type of behavior because of the cost of earning a bad reputation.

100. Note that both EPG and WPG workers who have negotiated to give all or part of their bonuses to their employers can behave opportunistically by threatening to quit right before the fourmonth period is complete. The goal of such behavior would be to recapture the employer's share of the bonus. 
become devoid of any value either in use or in exchange, and an EPG worker might as well throw any EPG vouchers away. ${ }^{101}$ The WPG worker would similarly be unable to bargain using the prospective bonus, but he would still find the voucher useful because he could secure the bonus without telling the employer; that is, the WPG would still retain its value in use.

This explanation has considerable appeal to economists because it suggests that, rather than irrationally failing to bargain to efficient Coasean outcomes, the workers and employers in this experiment were superrational and rejected the bargaining option because they correctly anticipated opportunistic behavior. ${ }^{102}$ Furthermore, even though opportunism may have prevented both schemes from assisting a worker in obtaining employment (that is, perhaps neither scheme had value in exchange), workers favored the worker-payment scheme over the employer-payment scheme because the former added $\$ 500$ to the value of any work obtained. This description is consistent with the findings that (1) there was little evidence of bargaining in either group, (2) only the WPG experienced improved employment performance, and (3) far fewer workers participated in the EPG than in the WPG. ${ }^{103}$

Nonetheless, there are a number of difficulties with this argument. First, the game-theoretic approach probably overstates the likelihood that one could engage in the process of extorting the bonus from the other party without suffering any personal cost. Robert Frank has stated that "people will often refrain from cheating not because they fear being caught, but because cheating simply makes them feel bad." ${ }^{104}$ As the number of individuals constrained by conscience increases, the probability that a bargained split of the bonus will be honored increases, thereby elevating the value of the employer-bonus program and the value in exchange of the worker-bonus program. Second, the opportunism argument cannot explain the finding that employers and employees failed to collect a significant number of bonuses that were already earned, even though the cost of so doing was trivial. Third, the opportunism argument suggests that the employer bonus would be worthless, yet we know that white female EPG workers did seem to obtain benefits from the bonus scheme.

101. The single exception to this statement is that the employer bonus will still have value if: (1) employees trust employers, and (2) employers promise to turn over the entire bonus to a newly hired worker who remains for four months. In essence, this approach converts the EPG bonus into a WPG bonus, although EPG workers cannot secure this advantage unless they strike a deal with their employer.

102. One of the bedrock assumptions of neoclassical economists is that individuals behave rationally. See Flanagan \& KaHN, supra note 27 , at 7.

103. Of course, if this explanation were universally true, then one would have to explain why anyone signed up for the EPG, since this program would have had neither value in use nor value in exchange.

104. Frank, If Homo Economicus Could Choose His Own Utility Function, Would He Want One With a Conscience?, 77 AM. Econ. Rev. 593, 602 (1987). 
Perhaps this fact suggests that employers believed white women to be less likely to behave opportunistically. Finally, the opportunistic threats might well be dismissed as not credible.

To understand this final point, consider the situation of a worker who attempts to secure all $\$ 500$ of the bonus after he and his employer have previously agreed to share the bonus equally. Three cases are possible. First, when he took the job, the worker was not influenced by the bonus; that is, his $\$ 250$ negotiated bonus share constituted a rent. Second, the worker took the job only because of the prospect of receiving the $\$ 250$ negotiated bonus share. And third, the worker took the job only because of the expectation of being able to extort some or all of the employer's negotiated share of the bonus. In the first case, working at his current job is clearly the worker's best option, and any threat to quit is not credible. In the second case, since the worker would not have accepted the job but for the bonus, the threat to quit is not credible because, by assumption, he will be worse off if he does not stay and receive his $\$ 250$ bonus share. Since it is clearly to the advantage of the worker in the second case to remain with the firm until the bonus is paid (although presumably he will quit thereafter), the employer will not be moved by the worker's threat to quit prior to the four-month cutoff. The situation in which a threat would be credible would be one in which taking the job was in the best interest of the worker only if he could extort some of the employer's share. That is the third case. Since none of the employer's share would be obtained without extortion and since another job or unemployment would otherwise be preferable, the worker might as well attempt to extort a portion of the employer's share and, if the attempt fails, quit the job. Presumably, case three represents only a small portion of the total number of cases. ${ }^{105}$ Of course, employers will not know which category applies to a particular worker, and workers will have an incentive to obscure their true situations. Nonetheless, if the total number of workers who are expected to fall into the third category is small, employers will heavily discount all threats.

105. Using the example in the text, we know that a worker whase value of remaining unemployed is $V_{u c}$ will not fall into category three if the wage $W$ is greater than $V_{u c}$ (the first case) or if $W+\$ 250>V_{u c}>W$ (the second case). A necessary condition for the worker to be in the third category is: $W+\$ 250<V_{u c}<W+\$ 500$. The symmetry of the second and third cases indicates that each represents a $\$ 250$ range of values. Since, without more information, it might seem that categories two and three would be of roughly equivalent size, as long as any workers fall into category one, then category three must include fewer than $50 \%$ of the cases. Moreover, the expected value of attempting to extort the remaining $\$ 250$ from the employer is less than $\$ 250$ because the category three worker cannot be certain his plan will be successful. This further shrinks the proportion of cases that fall into the third category. Finally, even among this shrunken set of eligible candidates for the third category, not all will be willing to engage in this form of behavior; some will be restrained by ethical qualms, and others want to avoid bearing the repercussions of mistreating an employer. 


\section{B. Asymmetries Between the Two Bonus Schemes}

The types of transaction costs discussed in Section A were probably lower in the setting of the Illinois experiment than in virtually any other real-world setting requiring negotiations. At least two other real-world settings presenting higher transaction costs come readily to mind. For example, victims of acid rain near the Vermont lakes would find the cost of organizing the victims and then finding and negotiating with the polluters simply too high. The optimal level of pollution would therefore not be generated.

Coasean predictions, based on the assumption of zero transaction costs, would be equally useless in the case of two disputing neighbors. What if, for instance, one man's manure pile prevents his neighbor from enjoying her sundeck? The transaction costs of reaching an accommodation would probably be lower than in the case of acid rain but would still likely be higher than those costs facing the parties of the Illinois experiment. First, unlike the case in the Illinois experiment, the two neighbors would be locked in a bilateral monopoly. Second, again unlike the parties involved in the Illinois experiment, the neighbors would not already be coming together to negotiate a contract. Moreover, the negotiations over the dimensions of an acceptable manure pile may well be more complicated than those involved in negotiating the distribution of a bonus.

Indeed, of the full array of cases discussed in Coase's own article-ranging from the problems of cattle ranchers and farmers to that of a confectioner and a doctor-not one can be found that can plausibly be deemed to have transaction costs that are lower than in the Illinois experiment. To find a case in which the transaction costs approximate the low levels in the Illinois case, one almost certainly must choose a situation with the following elements: (1) a competitive market exists, thereby minimizing the bilateral monopoly problem; (2) the parties must already have reason to come together to contract; and (3) the additional factor to be negotiated is relatively straightforward. Finally, if the example arises in a labor-market context, one presumably would need assurances about the level of activity in the market to ensure that the per-unit transaction costs were low.

In sum, to the extent that positive transaction costs explain the results of the Illinois experiment, it creates a powerful argument that the efficiency, invariance, and distribution predictions of the Coase Theorem have little relevance in the real world. Nonetheless, three asymmetries in this experiment potentially impair its usefulness as a test of the Coase Theorem. 


\section{Generating Co-Worker Demands}

An employer who gives favorable treatment to a newly hired EPG worker-by sharing some of the EPG bonus with the worker or simply providing the EPG worker with a higher wage-may risk inviting requests for similar benefits from other workers. If the employer were to accede to these demands, the value of the employer's share of the bonus would be reduced; if she resisted, she would be forced to pay the price of discontented workers. As a result, the benefit of bargaining with an EPG worker might be seriously impaired in a way that bargaining with a WPG worker would not. ${ }^{108}$ But once again, while this factor might explain why the employment performance of WPG workers surpassed that of EPG workers, it does not explain why so many EPG workers refused to participate. By informing employers of the possible $\$ 500$ bonus, EPG workers could enhance their own employment prospects, even if they could not bargain for the $\$ 500 .^{107}$

\section{Tax Considerations}

The differential tax treatment of money paid to workers and employers might also affect the outcomes of the two bonus schemes. Two separate tax issues are involved, both involving the effect of differential rates: the difference between the tax rate imposed on employers who receive bonuses, and the tax rate imposed on workers who receive bonuses; and the difference between the effective tax rate that applies for money received by workers directly in the form of a WPG bonus and the tax rate that applies when the bonus comes indirectly through bargaining with the employer. These two issues are conceptually distinct, and only the latter creates the type of asymmetry that could taint a test of the Coase Theorem.

\section{a. The Effect of Different Tax Rates on Employers and Workers}

Harold Demsetz clearly sets forth the first issue in a comment on an earlier draft of this paper:

106. Note that this problem would arise only if the employer shared some of her bonus with an EPG worker. (As mentioned above, there was no evidence that EPG workers were awarded higher wages.) If the employer kept the entire bonus herself, other workers would have no grounds for complaint. But if employers feel constrained not to bargain with EPG workers but are not similarly constrained with WPG workers, one might expect that the worker-payment scheme would generate superior employment performance.

107. While the results of the experiment indicate that the worker-bonus scheme was generally far more effective than the employer-bonus scheme, the ability of a WPG worker to use the bonus to bargain with an employer may also be restricted. One employer in Chicago who has participated in other government-sponsored incentive schemes to hire the hard-core unemployed informed me that his company would not accept cash payments from workers under any circumstance, as this would be deemed tantamount to bribery, presumably a corrupt practice. This consideration may simply mean, however, that concessions by WPG workers to their employers would have to come in the form of wage reductions rather than from lump-sum transfers. 
[I]t would be important to know the tax treatment accorded the supplemental vouchers. I suspect employers receiving these vouchers realize a smaller net because of the higher tax rate they pay than would be paid by employees receiving these vouchers. If the net gains to the two parties differ in this direction because of tax treatment we would expect statistics such as those produced in [this paper] even if the Coase Proposition were true. ${ }^{108}$

While this view is plausible, it turns out to be incorrect.

It may help to illustrate this issue with a simple example. Let us assume that employers are subject to a $50 \%$ tax rate and workers are subject to a $20 \%$ tax rate. These rates imply that an EPG employer who collects a $\$ 500$ bonus will receive a net gain of $\$ 250$ and a WPG worker who collects a $\$ 500$ bonus will receive a net gain of $\$ 400$. Does that imply, as Demsetz suggests, that one would expect superior performance in the WPG rather than the EPG? The simple answer is no. If the Coase Theorem is correct, the bonus money will flow to whichever party requires it to enable a Pareto efficient contract to be formed. If efficiency requires that the employer receive the entire bonus to induce the hiring of a worker, then the employer will receive a net gain of $\$ 250$ regardless of which bonus scheme is involved.

The case of an EPG worker is easy. She will simply agree to let the employer keep the entire bonus, which will be subject to the $50 \%$ employer tax rate, thereby leaving the employer with $\$ 250$ and the EPG worker with no bonus money. The case of the WPG worker is more complex. The worker will retain the entire $\$ 500$ bonus and agree to a wage reduction of $\$ 500$, thereby leaving the worker with no effective tax liability and no bonus money. The employer will have saved $\$ 500$ in payroll costs, leaving a net gain of $\$ 250 .^{109}$

The same showing can be made for the situation in which efficiency dictates that the worker receive all the bonus money. WPG workers will retain the $\$ 500$ bonus and receive a net gain of $\$ 400$. Because of the tax deductibility of wages, EPG employers can achieve this same result whether they retain the bonus or not. If the EPG employee retains the $\$ 500$ bonus, then the worker's wages will be increased by $\$ 500$. In this way, the employer incurs no effective tax liability from the bonus and confers a net gain of $\$ 400$ on the EPG worker. The EPG employer can achieve the identical result by simply transferring the $\$ 500$ to the worker. Accordingly, we have shown that differential tax rates for workers and

108. Letter from Harold Demsetz to Robert Schapiro, Editor-in-Chief, Yale Law Journal (May $25,198 \%$ ) (discussing Donohue aricle) (on file with author).

109. The combination of the worker's retention of the bonus with an equivalent reduction in wage iv designed to prevent double taxation. Without the offsetting wage reduction, taxes would leave the WPG worker retaining only $\$ 400$ of the bonus, thereby reducing what could be conveyed to the ernpluyer. 
employers will not affect the applicability of the Coasean identity prediction. This conclusion holds as long as bonus dollars that end up in the workers' hands are treated similarly whether they come directly from the government or via the employer. ${ }^{110}$ Furthermore, these tax considerations suggest that WPG workers might be constrained to retain their bonuses and only bargain over the wage while EPG workers would not be so constrained. To the extent that bargaining over the bonus is preferable to bargaining over the wage, these tax considerations lend an advantage to the EPG.

\section{b. The Effect of the Partial Nontaxability of Unemployment Compensation}

I have just shown that differential tax rates for workers and employers do not create an asymmetry in this test of the Coase Theorem. In fact, if WPG bonuses are treated as ordinary income by the Internal Revenue Service, then tax issues will create no asymmetry at all. On the other hand, at the time of the Illinois experiment, regular unemployment compensation benefits were given favorable tax treatment under the Internal Revenue Code, ${ }^{111}$ and the IRS would likely have accorded the same favored treatment to WPG bonuses. ${ }^{112}$ In this event, an asymmetry will exist if bonus dollars that are transferred to workers from EPG employers

110. The same rationale suggests that differing wealth effects between the employer and employee should make no difference to the Coasean prediction. That is, the fact that a $\$ 500$ bonus looms larger in the mind of an unemployed worker than in the mind of a hiring employer is irrelevant to the application of the Coase Theorem. The rationale is precisely the same as that set forth in the text. One can think of this wealth effect as analogous to a differential tax treatment that makes the bonus received by the employer (appear) smaller than that received by the worker.

For example, consider the situation in which Moneybags is trying to hire Jean Valjean. Presumably, the declining marginal utility of income is such that the $\$ 500$ is worth much more to the potential worker than to the rich employer. But this is exactly analogous to the situation in which any bonus money put into the hands of the employer is taxed while bonus money given to the employee is untaxed. Fewer bargains will be struck in this case than in the no-tax case, but the Coase Theorem would predict the same number of bargains regardless of which party is initially assigned the bonus.

111. In an influential 1974 article, Martin Feldstein argued that the fact that unemployment compensation benefits were untaxed while earned income was taxed increased the perverse incentive of unemployment insurance. Feldstein, Unemployment Compensation: Adverse Incentives and Distributional Anomalies, 27 NAT'L TAX J. 231 (1974). In response, the IRS persuaded Congress to amend the tax cade to provide for the partial taxation of unemployment compensation benefits. See 26 U.S.C. $\$ 85$ (1982). At the time the Illinois bonus experiment was undertaken, the Code treated onehalf of all unemployment benefits as taxable income for those with income exceeding $\$ 12,000$ if single and $\$ 18,000$ if married (whether or not the couple filed jointly). Prior to 1984 the limits had been $\$ 20,000$ for single taxpayers and $\$ 25,000$ for married taxpayers. Since January 1, 1987, all unemployment benefits have been taxed as ordinary income. Tax Reform Act of 1986, Pub. L. No. 99-514, $\S 121,100$ Stat. 2085, 2109 (codified as amended at 26 U.S.C. $\$ 85$ (1985)).

112. The IRS has excluded similar types of state welfare or transfer payments under a "general welfare" doctrine. See Rev. Rul. 72-340, 1972-2 C.B. 31 (stipends paid by city to unemployment probationers); Rev. Rul. 74-74, 1974-1 G.B. 18 (state benefits to victims of crime); Crane, Matching and the Income Tax Base: The Special Case of Tax Exempt Income, 5 AM. J. Tax PoL'Y 191, 233-35 (1986) (Internal Revenue Service has repeatedly relied upon "the general notion that general welfare payments should not be subject to federal income taxation."). 
do not receive similar favored tax treatment. ${ }^{113}$ The simplest case to consider is when a worker's income is below the amount at which unemployment compensation benefits are taxable. ${ }^{114}$ If efficiency required that the entire $\$ 500$ bonus be paid to the worker, this result could be effected if the bonus were paid directly to a WPG worker, who would then simply keep it without paying tax. If, however, the bonus were paid directly to an EPG employer, it would presumably be taxed as income when transferred to the employee. Thus, while low-income WPG workers could retain the entire $\$ 500$, an EPG worker could never retain this full amount.

It is important to understand, however, that the potential asymmetry created by possible differential tax treatment arises only when efficiency requires that bonus money be paid to workers. This situation occurs when jobs are available and workers must be compensated to forego the leisure associated with unemployment compensation. The asymmetry does not arise if the reverse condition holds and employers are the ones who must be compensated to induce them to hire the unemployment insurance recipients. In such circumstances, employers will end up with the identical amount of money whether the worker is in the EPG or the WPG. ${ }^{115}$ Consequently, the fact or expectation of differential tax treatment could reduce the effectiveness of the employer-bonus scheme vis-a-vis the worker-bonus scheme, but only in the circumstance in which bonus dollars were to be transferred to low-income workers. Furthermore, since the tax treatment of these bonuses was uncertain, possibly many EPG and WPG workers would simply fail to report their bonus income to the IRS, thereby escaping tax liability and restoring greater symmetry to the two bonus schemes. ${ }^{116}$

113. The theory supporting the asymmetrical tax treatment is that the payment of a portion of the EPG bonus to the employee is fully taxable compensation. One might still argue, under the general welfare doctrine, that such payments should receive tax treatment identical to that of WPG bonuses. If this argument were successful, the tax asymmetry would disappear.

114. The asymmetry illustrated in this example applies as long as WPG bonuses are treated as unemployment compensation and thus receive favorable tax treatment, while EPG bonuses that are transferred by employers to workers are taxed as ordinary income. Nonetheless, to get some sense of the number of workers whose earnings would be below the $\$ 12,000$ cutoff and thus not subject to tax on any unemployment benefits, I computed the yearly earnings of control group workers. The mean figures for male and female workers, which were projected from the first quarter of post-experiment earnings, were $\$ 14,258$ and $\$ 10,282$, respectively. In addition, $48.1 \%$ of the male workers and $63.7 \%$ of the female workers earned less than $\$ 12,000$.

115. The proof of this proposition is straightforward for low income workers who are not taxed at all on unemployment insurance benefits: WPG workers will receive the bonus tax-free, by assumption, and then confer it to their employers who will pay tax, or the state will confer the bonus directly to EPG employers who will then pay the same amount in tax. If the WPG worker exceeds the tax corde's income threshold and is therefore liable for some tax on unemployment benefits, the argument proceeds in the same manner as that set forth in Section IV(B)(2)(a) supra. Significantly, this asymmetry is not analogous to a situation in which the experiment called for employer bonuses of, say, $\$ 350$ and worker bonuses of $\$ 500$. In such a case, unlike the scenario posited in the text, if efficiency required all the bonus money to be transferred to employers, EPG employers could only collect $\$ 350$, while WPG employers could collect $\$ 500$.

116. If all workers failed to report the bonus income whatever its source, the symmetry would be complete. In 1982 less than $75 \%$ of taxpayers correctly reported their unemployment compensation 


\section{Stigmatization}

One essential difference between the employer-payment and the worker-payment bonuses is that the first could only improve job prospects of EPG workers if the workers revealed the existence of the bonus, while the latter could benefit WPG workers even if the workers did not inform potential employers. It is certainly possible that an employer, upon being told that the state of Illinois will pay a $\$ 500$ bonus for hiring a particular worker, might immediately wonder "What's wrong with this person?"117 Moreover, some individuals might feel embarrassed mentioning that they were receiving unemployment compensation. ${ }^{118}$ If the stigmatizing effect of the program is great, then once again neither the EPG nor the WPG would have any value in exchange, and only the WPG would have value in use.

\section{Factors Indicating Failure of the Coase Theorem}

The two preceding sections have set forth many plausible reasons for why the WPG would manifest superior results to the EPG in the various measures of labor-market performance presented in this paper. But only two of the explanations - the danger of opportunistic efforts to disgorge bonuses and the possibility of stigmatization-can explain why there would be so little interest in the EPG. Only these two factors undermine both the value in use and the value in exchange of the employer-payment scheme. But even if one believed in the significance of these explanations and therefore were convinced that many workers might have had a rational reason for ignoring the EPG, and even if all of the impediments to bargaining eliminated the value in exchange of the worker-payment

benefits, and one would imagine the figure could be substantially lower for the bonus payments because of the increased uncertainty about their tax treatment. 1 TAXPAYeR CoMpliance 59-60 (J. Roth, J. Scholz \& A. Witte eds. 198\%). Indeed, the 75\% figure, which is far below the $95 \%$ figure for reporting of wages and salaries, occurred despite the requirement that states inform the IRS of all unemployment compensation payments to individuals. 26 U.S.C. $\S 6050$ B (1988).

117. In the Dayton study, Burtless, supra note 63 , in which welfare recipients were furnished vouchers offering employers reimbursement for a substantial part of the workers' wages, job seekers with the vouchers were significantly less likely to find employment than were job seekers without vouchers. The author of the study noted that:

The same document that described the government's offer to pay up to one-half of the applicant's first-year wages and one-quarter of his or her second-year wages also informed employers that the applicant was a welfare recipient. Although the vouchered worker was offered at steep discount, employers appeared to interpret the voucher as implying "damaged goods." Id. at 113. Clearly, though, workers collecting unemployment compensation are of generally higher quality than typical welfare recipients, so the dangers of stigmatization would presumably be less in the Illinois experiment. In fact, the only direct indication of the possible effect of stigmatization in the Illinois experiment was that black males in the EPG qualified for bonuses at a lower rate than their control group counterparts. See Woodbury \& Spiegelman, Randomized Trials in Illinois, supra note 11 , at 525 .

118. Because of the attendant stigmatization, many individuals who are eligible for governmental benefits do not receive them. In 1970 only $69 \%$ of eligible families participated in Aid to Families With Dependent Children and only $38 \%$ of eligible individuals participated in the Food Stamp program. Moffitt, An Economic Model of Welfare Stigma, 73 Am. Econ. Rev. 1023, 1023 (1983). 
scheme, the validity of Coase's efficiency prediction still may be in trouble simply on the basis of the experience in the WPG. None of the factors discussed above in any way diminished the value in use of the WPG. Any WPG employee who satisfied the employment criteria of the experiment could secure a $\$ 500$ bonus at minimal cost and without risking opportunistic threats or stigmatization. But only about $60 \%$ of white WPG workers and less than $40 \%$ of black WPG workers who met these employment requirements collected bonuses. ${ }^{119}$ These outcomes strongly suggest the presence of irrationality and/or inefficiency. ${ }^{\mathbf{1 2 0}}$

\section{Ignorance}

In addition to the positive transaction costs and the asymmetries cited above that may undermine the identity prediction of the Coase Theorem, I suspect that many participants did not even realize that bargaining was an option. ${ }^{21}$ Indeed, some workers might have mistakenly feared that such behavior was illegal. Moreover, since employers were not apprised of the existence of the program and only learned of it when informed by job applicants, there was virtually no opportunity for employer advertising to alert workers that either bonus scheme could help them get both a job and a possible side payment if they bargained with the employer. ${ }^{\mathbf{1 2 2}}$

119. See Table IV supra.

120. The failure to collect a bonus for which one ultimately qualified might stem from an ex ante assessment that the expected value of the $\$ 500$ bonus-which had to be discounted by the probability that it would be obtained-was not worth the cost of program participation. For WPG workers, there was little risk of opportunistic threats or stigmatization. Therefore, given the relative costs and benefit: of participating, for these workers, the view that their failure to collect bonuses was cost effective seems highly improbable.

121. As noted supra notes 67-68 much of the economic literature concerning schemes to subsidize workers or employers overlooks the possibility of bargaining, as did the Final Report of the Illinois Experiment, sec R. Spiegelman \& S. Woodbury, Final Report, supra note 11, at $\mathrm{x}$. This finding lends credence to Daniel Farber's suggestion that the problem with the Coase Theorem is that it is too brilliant. He writes:

If the idea that victims bribe polluters is startling, people are not likely to think of it themselves; if they do not think of it themselves, they are not likely to do it. If only a brilliant person can think of doing something, it is unlikely that most people will adopt that course of conduct. Most people, after all, are not brilliant.

Farber, The Case Against Brilliance, 70 MinN. L. Rev. 917, 919-20 (1986). It is therefore unlikely that the public will realize the implications of the Coase Theorem and act accordingly without specific instructions. In fact, experimental tests that have supported the Coase Theorem have given very explicit instructions about the use of bargaining to achieve efficient outcomes. Moreover, these tests have invariably used college or graduate students as the subjects, who are probably of higher average intelligence than the population at large, although not uniformly so. See sources cited supra note 8.

122. Wrthout this realization EPG workers might not understand that they could benefit from beng in the program, and WPG workers might think that the program did nothing to make them more attractive to tmployers. Presumably, if the incentive scheme were implemented widely, employers like McDonald's could advertise for bonus workers, thereby reducing the distorting effects of worker ignorance.

Another possubility is that the worker's "ignorance" is rational. Even if the proximate cause of the fuilure to bargan was the general failure to recognize this option, this failure may be because individuals have learned that bargaining does not work in such settings. Consider, for example, how surprised someone sitting in a subway seat would be if a rider asked to purchase the subway seat or the response of a restaurant customer if a fellow patron attempted to bribe her to put out a cigarette. 
But the absence of bargaining cannot explain the massive underuse of the employer-payment scheme, unless job vacancies were so prevalent that employment could easily be obtained, which seems unlikely. In other words, even if constraints on bargaining undermine the value in exchange of both types of bonus payments, they still retain their value in use. ${ }^{\mathbf{1 2 3}}$ One would only expect the widespread underuse of the employer-payment scheme to occur if EPG workers did not believe that the bonus scheme could improve their employment prospects. Thus, while transaction costs may be relatively low for those who realize that bargaining is possible, ignorance can render the employer-payment scheme worthless if it prevents workers from perceiving the bargaining option and obscures that the employer bonus can still aid them in securing employment.

\section{Accepting Authoritarian Determinations}

From the perspective of the participants in the Illinois experiment, the decision to confer the $\$ 500$ bonus on either the worker or the employer might be deemed to reflect an underlying policy judgment on the part of government officials. While the participants might not understand or care about the rationale behind this judgment, they might feel bound by this authoritarian pronouncement as to who should receive the bonus. In this event, the bonus might be thought of as an entitlement of the one to whom it is paid or as a resource that one is "entitled" to have according to a legislative determination. Any attempt to deprive the employer of an EPG bonus through bargaining might be viewed as rejecting this authoritarian judgment. ${ }^{124}$ In other words, the existence of an authoritarian determination about the recipient of the bonus might create a presumption of inalienability. Consequently, bargaining would be deterred, although the employer-payment scheme would still have the potential to enhance employment prospects.

\section{Altered Psychology of Bargaining}

While the Coase Theorem predicts equal distribution of income between employer and employee in the two experimental groups, the assign-

While such behavior is the necessary prerequisite to the attainment of the efficient allocation of the subway seat and of the restaurant's air and would therefore be the delight of all Coaseans, it might well generate a rather hostile response, which at the least would escalate bargaining costs sharply.

123. Even if the law barred workers from attempting to extract any of the employer bonus from prospective employers, the employer-bonus scheme would still render EPG workers more valuable to employers than they would be without the bonus. More valuable workers obtain work more readily and tend to be offered better or higher paying jobs.

124. Interestingly, one experimental test of the Coase Theorem revealed that experimenter pronouncements that lent moral authority to a particular initial entitlement influenced the ultimate bargain to the advantage of the initial owner. Such a finding is inconsistent with the notion of a selfregarding rational economic actor, who would seek to obtain the best possible deal without concern for the moral legitimacy of his gains. See Hoffman \& Spitzer, Entitlements, Rights, and Fairness, supra note 8 , at 154 . 
ment of the initial right to payment may have affected the psychology of the bargaining agents in a way that enabled the nominal owner of the right to secure a more favorable distribution of income. ${ }^{125}$ Thus, WPG workers, buttressed by the aforementioned authoritarian determination, might have felt stronger in the negotiations because the payment was being made to them, while EPG workers might have perceived themselves to be at a bargaining disadvantage since the bonus would be paid directly to their employers. ${ }^{126}$ But this factor could only affect the distribution of rents between the parties, not the decision to enter an employment contract in the first place. ${ }^{127}$ Therefore, while the psychological effect of this initial assignment of the bonus might undermine the Coasean prediction of equal distribution (which cannot be examined directly since no information on the actual distribution of the bonus was collected), it does not alter the efficiency or invariance predictions.

One could argue that this psychological factor might have influenced the decision to participate in the Illinois experiment and thus contributed to the superior performance of the WPG. Specifically, some workers might not have been willing to search for work if the expected value of their search was less than the benefits of remaining on the unemployment rolls. While the possible enhanced bargaining power resulting from being in the WPG as opposed to the EPG would not have increased a WPG worker's chance of getting a job, it might have increased his earnings if a job had been secured, as a higher proportion of the rents generated by the employment match and bonus would have been retained by the worker. ${ }^{128}$ If this factor had been significant, then the increased expected value of job search might have been sufficient to induce some marginal workers to participate in the bonus experiment who would otherwise prefer simply to collect unemployment without looking for work. ${ }^{129}$ Accordingly, participation in the WPG would increase, generating greater job search and supe-

125. One experimental study found that in a bargaining situation between parties $A$ and $B$, a contract presumption favoring A will tend to generate a more favorable outcome for A. Schwab, supra note 8 While the classroom experiment seems to refute "the Coasean hypothesis that rules of contract interpretation do not affect the distribution of wealth between bargainers," $i d$. at 265 , it is consistent with the better performance of WPG workers vis-a-vis EPG workers found in this study.

126. While these feelings might seem irrational, an EPG worker may have felt that bargaining over the distribution of a bonus paid by the state to the employer would have untoward consequences for the incipient employment relationship.

127. An analogy to two different types of auctions may be helpful. In the usual auction, the bidding starts low and ends with the highest bid. In top-down auctions, the seller sets a high price which is then dropped periodically until a buyer accepts the price. While neither scheme should affect whther the good is sold, they will affect the division of any surplus (rents) between the buyer and seller whenever there is a substantial difference in the reservation prices of the top two bidders.

128. Moreover, as long as there is any cost associated with bargaining, then the expected value of search would be higher for WPG workers because in the event they were offered a job outright they would be able to keep the entire bonus without resorting to any bargaining.

129. Again using the analogy of the auctions, if buyers prefer the normal bidding auction because they capture more of the rents, more buyers may show up at such auctions as opposed to top-down auctions, which may then influence whether the goods are sold at all. 
rior employment performance. This factor, however, cannot be the major explanation of the widely disparate results found in this experiment for two reasons. First, it implicitly assumes that both bonus schemes would generate identical employment performance if used and that the only stimulus for better WPG performance comes though increased participation. Yet the evidence shows that WPG performance was superior even controlling for the level of participation. ${ }^{130}$ Second, this factor only operates on the margin, while the true explanation for the vastly greater preference for the worker-bonus scheme is almost certain to affect a wider spectrum of program participants.

\section{Imperfections in the Labor Market}

The analysis in Section II(B) demonstrated that the Coase Theorem predicts identical outcomes for the two bonus payment schemes, assuming the labor market was perfectly competitive. But implicit in the model of perfect competition is the prediction that unemployment, which is one of the problems that the bonus schemes were intended to address, cannot occur, since falling wages will always serve to bring the supply and demand of labor into balance. Many economists have argued that the minimum wage prevents this equilibration from occurring and that the identity prediction will be undermined by such a labor market constraint. ${ }^{131}$

Figure IV depicts the supply and demand for labor which would, in the absence of the minimum wage, $W_{m}$, yield an equilibrium wage of $W_{1}$ and an equilibrium quantity of workers, $Q_{1}$.

130. See supra note 69 and accompanying text.

131. See Lerman, supra note 63, at 159. 
Figure IV

The Effect of the Two Bonus Schemes with a Minimum Wage Constraint

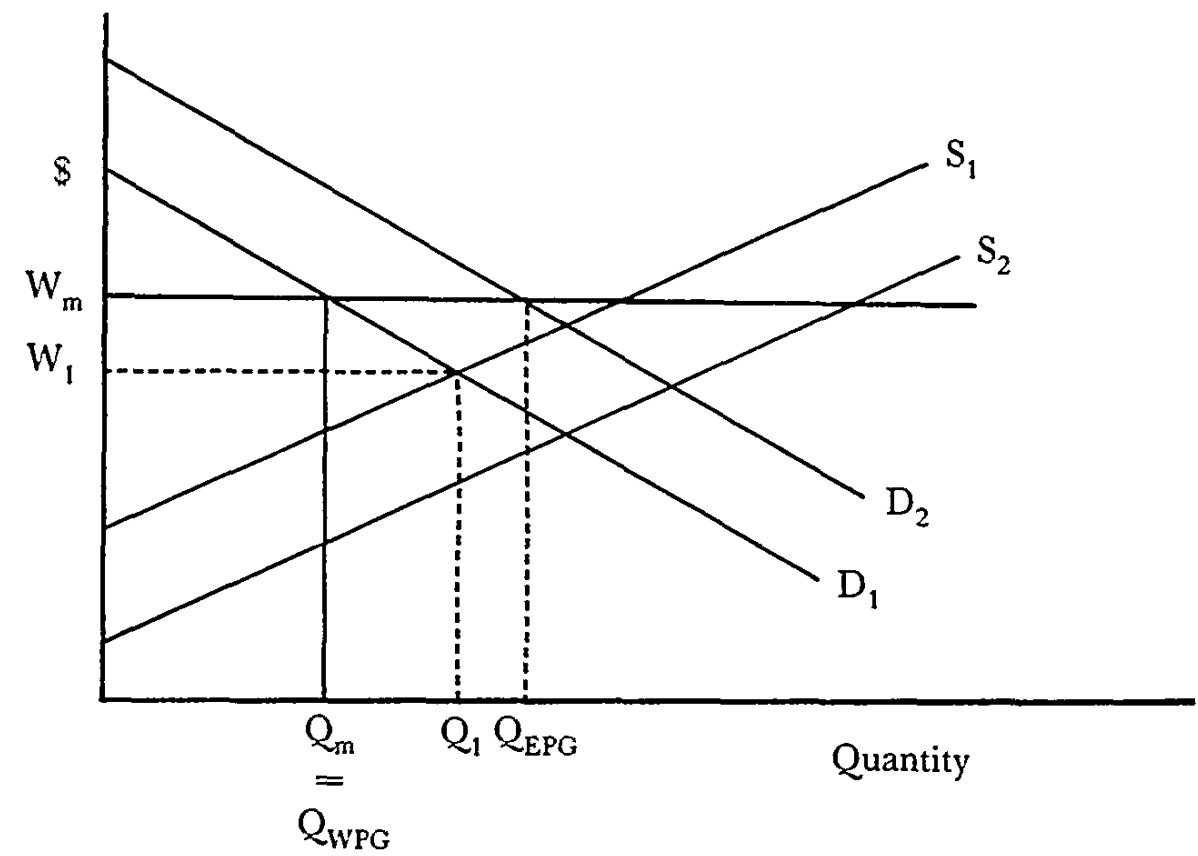

The minimum wage generates a new equilibrium where the minimumwage constraint intersects the demand curve, thereby reducing the number of workers hired to $Q_{m}$. As we saw in Figure I above, one can think of the employer-payment scheme as shifting the demand curve for labor from $D_{1}$ to $D_{2}$ and the worker-payment scheme as shifting the supply curve for labor from $S_{1}$ to $S_{2}$. But owing to the minimum-wage constraint, only the rightward shift in the demand curve will cause an increase in the number of workers hired, since the equilibrium level of employment will be determined by the intersection of the demand curve and the minimum-wage constraint. Accordingly, under such a labor-market constraint, the employer-payment scheme can increase the level of employment, but the worker-payment scheme will be totally ineffective in that regard. ${ }^{\mathbf{1 3 2}}$

The minimum-wage constraint cannot explain the results observed in this experiment, however, since the primary result was that the EPG did not do as well as the WPG in obtaining employment quickly. Therefore,

132. This analysis assumes that the minimum-wage constraint cannot be circumvented by an employee's making a side payment to the employer. Thus, if an employer would be willing to hire a WPG worker only if the employer could pay less than the minimum wage, I assume that the Fair Labor Standards Act would prohibit the hiring of the worker at the minimum wage contingent upon receiving a share of the WPG worker's bonus. 
according to the results of the Illinois experiment, the minimum-wage constraint probably was not the dominant factor in slowing the rehiring of unemployment compensation recipients. ${ }^{133}$

\section{Conclusion}

The confidence of many commentators and policymakers in the ability of the market to generate efficient outcomes is well known. Some would even claim that the power of the market is so great and unyielding that it resembles a surging river that overruns all obstacles. ${ }^{134}$ The results of several highly controlled tests of the Coase Theorem have supported this vision of the market. ${ }^{135}$ Following their discussion of the results of one such test, Hoffman and Spitzer draw strong conclusions about the predictions of the Coase Theorem:

One implication of our results is that policymakers should recognize the power of voluntary agreements to overcome externality problems, even in the absence of government intervention. More specifically, these results produce a presumption in favor of the Coase Theorem. . . By a "presumption in favor of the Coase Theorem" we mean that a judge or legislator who is considering choosing a rule to govern a dispute in tort, contract, or property ... should assume that the parties can and will exhaust the gains from trade by voluntary agreement. One who would show that bargaining breakdown is likely must bear the burden of proof. ${ }^{\mathbf{1 3 6}}$

Perhaps the results of the real-world experiment discussed in this Article will at least prompt reconsideration of whether a presumption in favor of the Coase Theorem should universally apply. Whether the divergent results simply demonstrate the presence of positive transaction costs and asymmetries in the two bonus schemes (that is, reflect rational responses to different incentives) or whether the results actually reveal inadequacies in the Coase Theorem cannot be definitively resolved. Nonetheless, there was no evidence of the high degree of bargaining necessary to effectuate the Coasean identity prediction. Because a large number of individuals apparently did not recognize that both bonus schemes could aid their job search and provide them with bonus dollars, participation rates were

133. A worker earning the minimum wage of $\$ 3.35$ an hour for 40 hours a week would earn $\$ 1,742$ in a quarter. In the quarter after the first spell of unemployment, only $27.4 \%$ of control-group men and $38.1 \%$ of the control-group women earned less than $\$ 1,742$. Moreover, a number of these low earners might have been above-minimum-wage workers who did not work full-time or for the entire quarter.

134. Kelman, Consumption Theory, Production Theory, and Ideology in the Coase Theorem, 52

S. CAL. L. REv. 669, 675 (1979).

135. See sources cited supra note 8 .

136. Hoffman \& Spitzer, Large Bargaining Groups, supra note 8, at 151. 
lower than one might have expected, particularly in the EPG. ${ }^{137}$ Moreover, a sizable number of workers and employers seem to have passed up free money by failing to claim bonuses to which they were entitled. ${ }^{138}$

Still, the nature of this experiment was necessarily short-term, and the one-shot character of the bonuses suggests that the parties may have had insufficient opportunities to learn to deal with this incentive program. It would almost certainly be the case that with greater instructions about bargaining or simply with the passage of time in a continuing program, more individuals would learn to respond in a way that would further their interests. ${ }^{138}$ This reasoning suggests, though, that when rendering judgments in one-shot Coasean bargaining situations-such as nuisance cases-judges should explicitly instruct the parties that they have the ability to reverse inefficient outcomes through bargaining. Without such information the parties may fail to recognize the existence of such an option.

The results of the Illinois experiment also raise questions about the use of the Coase Theorem in some judicial decisions. For example, the Seventh Circuit Court of Appeals confronted a situation in which an employee received an incentive bonus of shares of stock to be delivered in ten annual installments beginning at the end of his employment. One condition of receiving the bonus was that the company would terminate future installments of the bonus if the employee ever engaged in competition with the company. Judge Posner, writing for the Court, noted the Coasean nature of a covenant not to compete and an inducement not to compete:

[1]t can be argued that under either arrangement, which is to say whatever the initial assignment of rights-whether the employer has the right to prevent the employee from competing or the employee the right to compete but at some previously determined price-the parties, because there are only two of them (so that the costs of transacting should not be prohibitive), will be able to bargain their way to the position that maximizes their joint wealth. ${ }^{140}$

If employers and workers are negotiating covenants not to compete at the initiation of the employment relationship, then the parallels with the Illinois experiment are clear: Only two parties must bargain, and they are not locked in a bilateral monopoly. Given the results of the Illinois study,

137. Sie supra text accompanying notes 57-61.

138. See supra text accompanying notes 62-65.

139. My guess is that, while perfect comprehension would lead to more equal results between the two groups than were observed in this experiment, the factors discussed above that favor the WPG over the EPG would not be rendered impotent by a greater understanding of bargaining and the Coase Theorem. This prediction could be tested if the Illinois experiment were repeated and the participants were given instructions on the use of bargaining to secure jobs and bonuses.

140. Sarnoff v. American Home Prod. Corp., 798 F.2d 1075, 1083 (7th Cir. 1986) (citing Coase, supra note 1). 
Judge Posner may be too optimistic in believing that efficient outcomes will be reached through bargaining. Moreover, if the covenant not to compete were negotiated after the employment relationship had been formed-as in the Sarnoff case-then a bilateral monopoly situation would exist since there would have been only one other party with whom each party could have negotiated over this issue. Since the Illinois experiment documents the failure of Coasean predictions even in the absence of bilateral monopoly, then a fortiori there would be grounds for caution in predicting efficiency in the employment context of Sarnoff, where the problem of bilateral monopoly was present.

Finally, the Illinois experiment sheds light on the importance of theory in resolving difficult policy questions. Although this experiment was designed to tell us whether supply or demand factors were responsible for the high costs of the Illinois unemployment compensation program, the view of labor markets expressed by Judge Posner in Sarnoff renders the entire enterprise futile. The bonus money in such a world would simply flow to where it was most needed, and supply and demand effects would be indistinguishable. Therefore, to the extent that the lack of bargaining undermined the prediction of the Coase Theorem, it was fortunate for the Illinois experiment because the ostensible unwillingness of the parties to bargain permits us to draw some conclusions about whether workers are more likely to leave unemployment if they or their employers are offered a bonus. In the Coasean world of zero transaction costs there would be no difference between these options. 
Appendix

Earnings Regressions For Male and Female EPG and WPG Workers

Dependent Variable: Earnings for the first full quarter after leaving the unemployment rolls.

Indep. Variables

Male EPG Female EPG Male WPG Female WPG

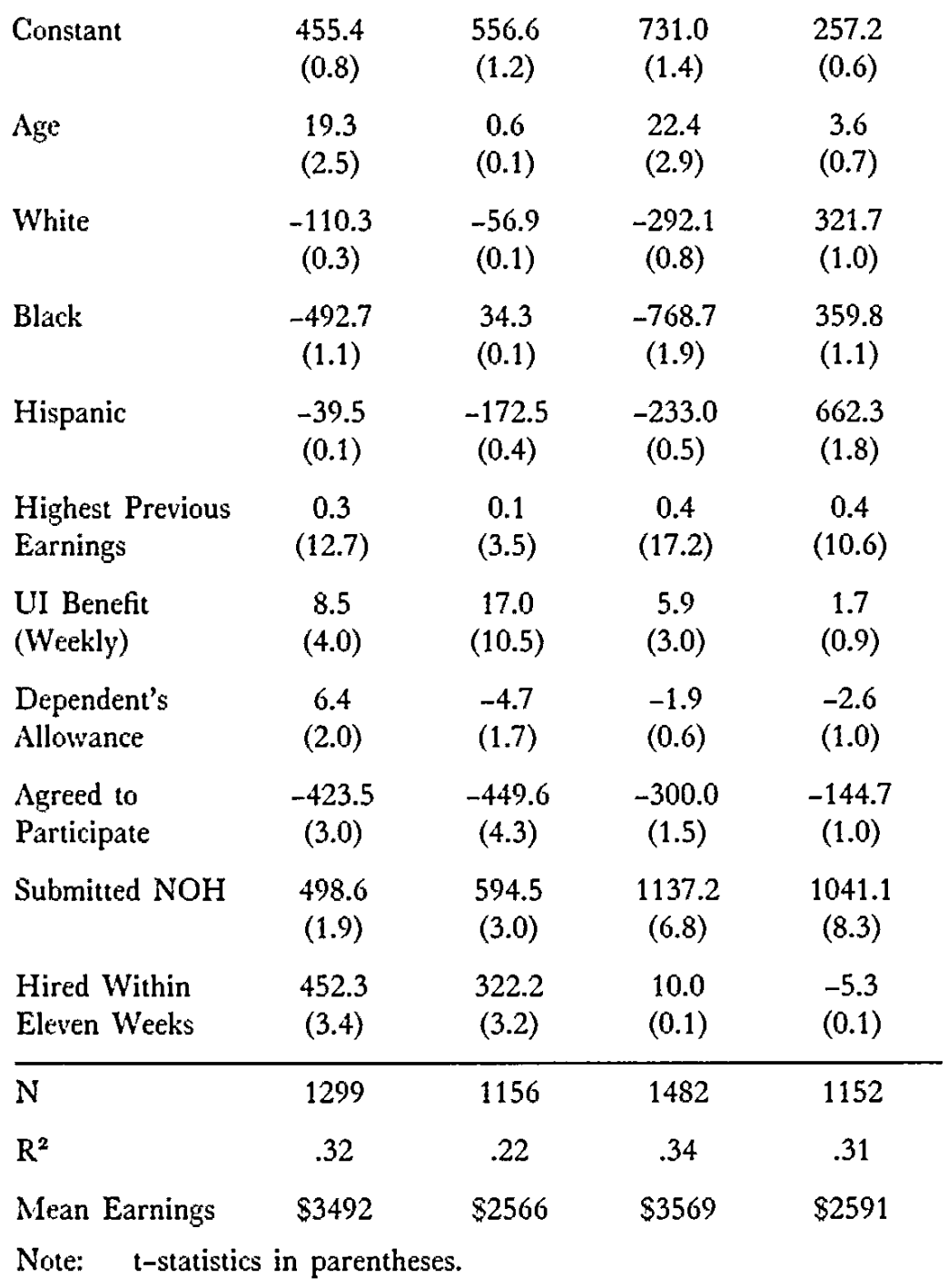


HeinOnline -- 99 Yale L.J. 610 1989-1990 